\title{
El pasado verificado y el futuro imaginado de la tradición alfarera de Nicoya, Costa Rica
}

The verified past and imagined future of the ceramic artisan tradition of Nicoya, Costa Rica

Anayensy Herrera Villalobos

Centro Científico Tropical de Costa Rica

anayensyherrera@gmail.com

Jim Weil

Museo de Ciencias de Minnesota, Estados Unidos de América

jimweilanthro@gmail.com

\author{
ALFARERÍA POPULAR, LA MEMORIA EN LAS MANOS \\ MONOGRÁFICO COORDINADO POR ELENA FREIRE PAZ (Universidad de Santiago de Compostela)
}

\section{RESUMEN}

La herencia alfarera en Nicoya, Costa Rica, ha perdurado por siglos al amparo del trabajo de las mujeres en sus casas. Sobrevivió como una industria de vajilla doméstica en la época colonial española. En el contexto socioeconómico de los últimos sesenta años debido al estímulo del turismo, las artesanas y los artesanos generaron un renacimiento de los estilos antiguos e inventaron nuevos. La pandemia por Covid-19 redujo el turismo y plantea serios retos para la producción alfarera y para quienes se dedican a esta tradición. Este artículo presenta una revisión histórica comprensiva y reflexiona sobre su futuro, imaginado por los propios actores.

\section{ABSTRACT}

The ceramic artisan heritage in Nicoya, Costa Rica, has endured for centuries in the shelter of women's work in their homes. It survived as a domestic ware industry in the Spanish colonial era. In the socioeconomic context of the last sixty years, under the stimulus of tourism, female and male artisans generated a revival of ancient styles and invented new ones. The Covid-19 pandemic reduced tourism and posed serious challenges to ceramic production and to those dedicated to this tradition. This article presents a comprehensive historical review and reflects about its future, as imagined by the actors involved.

PALABRAS CLAVE

herencia | tradición alfarera | Costa Rica | Nicoya

KEYWORDS

heritage | artisan tradition | Costa Rica | Nicoya

\section{Una herencia dinámica}

La Península de Nicoya en Guanacaste, Costa Rica, es el escenario de diversos saberes ancestrales y producciones artesanales. Algunos se remontan al pasado antiguo y otros están relacionados con las actividades económicas surgidas en las últimas cinco centurias. El Estado costarricense en atención de las convenciones de la UNESCO para salvaguardar la diversidad cultural, destaca y revaloriza artesanías y otras tradiciones como patrimonio cultural inmaterial, configurándolos como conocimientos antiguos, auténticos y representativos de la identidad cultural de los pobladores.

La alfarería que se practica en San Vicente y Guaitil, dos comunidades focales, utiliza técnicas de trabajo alfarero basadas en conocimientos transmitidos por generaciones y el uso continuo de las mismas fuentes de materias primas, compatibles con un origen que se remonta hasta tiempos prehispánicos (Weil y Herrera 2014). Es probable que la disponibilidad de arcillas finas favoreciera tanto la producción y uso en el ámbito local donde prevaleció, como su consumo a nivel regional. Además del barro, la presencia de curiol, nombre vernáculo para referirse a las arcillas de colores, distingue esta zona. La cerámica ganó reconocimiento por su calidad y belleza, no solo por su utilidad para preparar y guardar alimentos. La continuidad de esta tradición en ese espacio geográfico se basa en el principio que la gente selecciona aquello del pasado que tiene vigencia en el presente, por lo que el presente nos permite reconocer el pasado. En este sentido, la tradición es "continuidad recreada y (a la vez) cambio" (Marcos 2010: 3). 
Fuera de estas comunidades, la alfarería se practicó también en otros lugares de Nicoya, pero conforme no hubo reemplazo generacional, la actividad se perdió. Aún permanecen alfareras casi desconocidas en Moracia y Corralillo de Nicoya, y otras en auge en Puerto San Pablo de Nandayure. En la década de 1990 murió la última alfarera de Isla de Chira (Guier 2007). En Matambú, territorio indígena de origen chorotega designado como tal por el Estado en 1977 (Stocker, 2000), se había dejado de practicar hace unas décadas. Actualmente la alfarería está renaciendo con elementos no tradicionales.

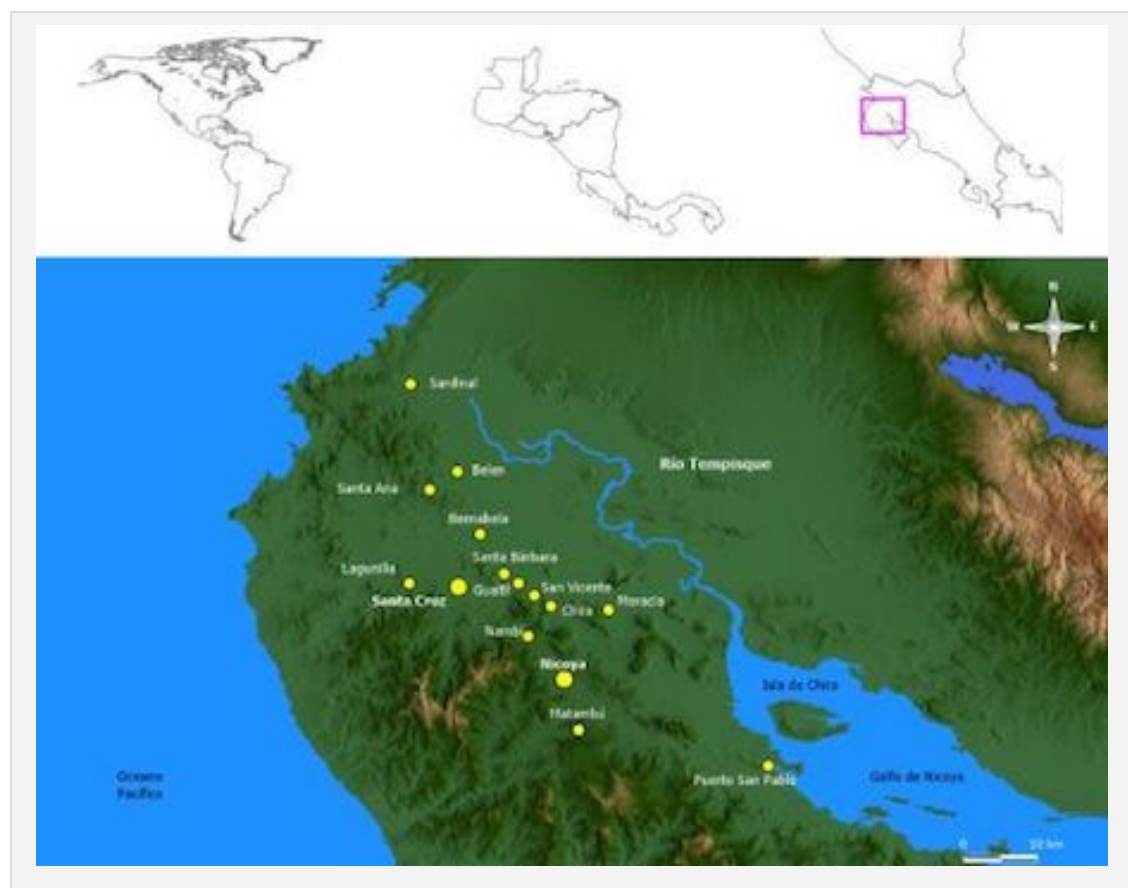

Zona de estudio y localidades mencionadas con referencia a Costa Rica.

Un recorrido por la historia de la tradición permite comprender la creación alfarera desde la perspectiva de la vida de San Vicente y Guaitil. ¿Por qué persiste esta tradición en esta zona? ¿Qué factores favorecieron dicha persistencia? ¿Cómo ha influido en estos procesos el fenómeno transformador de turismo?

Existen lagunas de información, especialmente durante la conquista y colonización española. Sin embargo, la vida doméstica favoreció trabajos y conocimientos esenciales para la sobrevivencia rural. La alfarería tradicional persistió porque otras costumbres alimenticias y religiosas, así como el trabajo agrícola y ganadero, continuaron y demandaron de ellas. Fue un todo articulado que funcionó a nivel de costumbres y creencias enlazadas en las actividades y valores simbólicos sobre la alfarería como expresión de la herencia cultural. El imaginario popular de los pobladores de Guanacaste reconoce una herencia indígena chorotega asociada con la creación de la alfarería.

Hasta la mitad del siglo XX, las casas fueron los talleres donde se perpetuó la práctica alfarera. Más tarde, la expectativa del turismo propició la creación de cooperativas y talleres colectivos que diversificaron la producción, los procesos innovadores en la manufactura, los diseños y motivos. A partir de la última década del siglo, los esfuerzos para crear un ecomuseo convocaron a su vez, procesos de fortalecimiento de la identidad cultural y en esa piscina de estímulos se gestó la expresión de la alfarería que hoy día perpetua el nombre chorotega.

El Estado costarricense interviene con una visión institucional donde existe poca participación comunitaria. A la vez, la pandemia por Covid-19 ha producido una disminución dramática de las ventas; por lo tanto, se exacerban todos los desafíos que afectan directamente la sobrevivencia de los artesanos, su bienestar y el sentido mismo de hacer alfarería. Una pregunta surge con respecto al futuro. ¿Existe una mañana para la tradición alfarera de Nicoya?

\subsection{Contexto geográfico e histórico}

Costa Rica se localiza en el istmo de América Central. El noroeste de Costa Rica abarca la provincia de Guanacaste y la península de Nicoya; también se conoce la región como Nicoya. Este es el nombre del cacique chorotega en uno de los asientos de la colonia española en el siglo XVI. 
Desde una perspectiva histórica hasta 1950 aproximadamente, el Estado costarricense hizo poco en las zonas rurales. La riqueza del país se centraba en la producción de café y banano. Los campesinos estaban en una economía de subsistencia, con una organización básica y recursos escasos. A partir de 1950 y hasta 1980 el Estado creció y se fortaleció en una estructura social demócrata con amplia participación en las distintas actividades. A partir de los años ochenta, Costa Rica aceptó políticas neoliberalistas con la privatización de algunas organizaciones y empresas públicas (Edelman 2005).

\subsection{Estado y pandemia}

El Informe del Estado de la Nación 2020 comienza con un dictamen claro:

“De experimentar una 'coyuntura crítica', según el Informe Estado de la Nación 2019, que entrañaba serios riesgos para la sostenibilidad del desarrollo humano, Costa Rica ha pasado a vivir una grave crisis que amenaza logros históricos de ese desarrollo. (...) Aunque la pandemia de covid-19 ha impactado a todo el mundo, en Costa Rica ha materializado los riesgos a la sostenibilidad del estilo de desarrollo nacional" (PEN 2020: 37).

El actual presidente Carlos Alvarado inició su mandato en 2018 con una ambiciosa reforma fiscal acorde con los lineamientos del Fondo Monetario Internacional. La pandemia no permitió ver los efectos esperados y en su lugar aumentó la brecha del financiamiento. En 2021 se observan los efectos de la pandemia con un alza históricamente alta del desempleo y subempleo, lo que ha ocasionado caída en ingresos de los hogares, insolvencia de las finanzas públicas por desbalance entre ingresos tributarios y gastos públicos por pandemia y deuda externa. En 2021, Costa Rica tiene una población proyectada de 5.163.021 individuos de los cuales 399.409 viven en la provincia de Guanacaste (www.inec.go.cr), donde el turismo es una de las principales actividades económicas. En 2019 el número de turistas fue de 3.139.008 a nivel nacional; 190 mil pasajeros de avión ingresaron al país en abril del 2021, una recuperación parcial después del paro por la pandemia (ICT 2021).

\section{Aproximaciones a la tradición alfarera}

La tradición es un concepto comprensivo que abarca todas las prácticas sociales junto con los conocimientos y sentimientos que forman componentes de la cultura de un grupo específico a través del tiempo. La herencia cultural enfatiza el contenido de una tradición y las circunstancias que plasmaron las experiencias de sus practicantes en lugares y tiempos específicos. Hoy en día la herencia alfarera de Nicoya es reconocida no solo por quienes la portan, sino que, dentro del contexto nacional, se vuelve un acto político que se declara como patrimonio cultural de la nación.

Más allá de las interacciones materiales y sus manifestaciones económicas y políticas, la confección de objetos con las manos y con herramientas sencillas muestra el desarrollo de la cultura expresiva. Se trata de herencias neuromusculares y procesos mentales visibles en el momento presente. Así la artesanía crea piezas únicas que, aunque se repitan, nunca son exactamente iguales. Recoge una tradición que persiste como herencia cultural particular de un espacio (Nicoya), un tiempo profundo que se remonta a las primeras ocupaciones humanas del territorio y presenta una continuidad que se manifiesta gracias a las estructuras de parentesco mediante usos cotidianos con sentido para distintos grupos sociales.

Entre los grupos sociales se incluyen las propias comunidades que mantienen la tradición; los grupos locales en lo regional y lo nacional que se interesan en piezas que les recuerda a su familia o localidad. El Estado hace exaltación de las tradiciones artesanales como símbolos de la historia y la identidad nacional; la labor institucional se dirige a la promoción cultural de los pobladores, sus comunidades e individuos y a la exhibición en museos o galerías. Otro grupo social son los turistas consumidores de bienes étnicos, interesados en el consumo de productos con identidad y autenticidad (Brulotte 2012).

El presente estudio de caso trata de una historia continua que se originó con los pueblos indígenas que ocuparon la región antes de la colonización española hasta la actualidad La herencia alfarera y su industria casera actual existieron antes del turismo y luego se impulsaron con este dentro de la economía capitalista global. Los recursos de la etnografía son importantes para conocer de primera mano los momentos de transformación ocurridos en los últimos cien años. A finales de enero de 2021 los suscritos visitamos doce talleres ubicados en Guaitil y los barrios Centro, Rincón, Progreso y Silencio de San Vicente; entrevistamos a 21 artesanos. Las entrevistas fueron abiertas, pero concluyeron con las 
preguntas: ¿Cómo ve el futuro de la tradición alfarera? ¿Puede pensar en una palabra que lo resuma? Una revisión de la trayectoria histórica y una consulta a los actores pretenden plasmar los principales retos de los artesanos y el futuro de alfarería en Nicoya.

\section{El pasado verificado}

El istmo sur de América Central es parte de la denominada Área Intermedia y Baja América Central (Lange 2004). La lingüística planteó el desarrollo endógeno de pueblos de habla chibcha en el territorio de Costa Rica y Panamá, desde donde se expandieron hasta Honduras y Colombia (Constenla 1991). La genética formuló la evolución local de tales grupos con mutaciones producto de cruces endogámicos (Barrantes 1993). Las migraciones mesoamericanas serían un fenómeno tardío y la zona, el escenario del desarrollo de pueblos chibchas (Fonseca y Cooke 1993).

Albert Norweb definió la subárea Gran Nicoya como formada por la vertiente del Pacífico de Nicaragua y el noroeste de Costa Rica y la postuló como la zona periférica sur de Mesoamérica (Norweb 1964). Los sectores norte y sur muestran a lo largo de la ocupación menos vínculos entre sí y más con sus vecinos (Dennett y otros 2019). Los pueblos antiguos situados en lo que hoy es Nicaragua mantuvieron vínculos fuertes con pueblos lencas de Honduras y El Salvador (Braswell y otros 2002, McCafferty y Dennett 2013). Nicoya participó con otros grupos chibchas de Costa Rica de relaciones que permitieron el acceso a jadeíta como materia prima y objetos acabados olmecas, epiolmecas y mayas del clásico temprano (Reents-Budet y otros 2017).

A partir del 800/1000 d. C. la presencia de individuos con deformación craneal y limadura dental tanto en la isla de Ometepe como en Bahía Culebra son claros signos de la presencia de individuos mesoamericanos (Solís y Herrera 2011). Sin embargo, el territorio fue escenario de distintos procesos de mestizaje y convivencia pluriétnica (Salgado y Vázquez 2006, Ibarra 2020).

\subsection{La antigüedad de la herencia}

La cerámica se preserva muy bien en el trópico; como herramienta de estudio permite comprender la dinámica cultural pues expresa los conocimientos tecnológicos, las pautas culturales y es relevante para constatar las raíces de la tradición alfarera en Nicoya (Herrera 2001).

Las primeras cerámicas surgidas en el sur de América Central se asocian con la agricultura de granos y tubérculos alrededor de 2000/1800 a. C., a la vez que comparten horizontes estilísticos considerados como indicadores de mundos semióticos compartidos (Reyes 2009). Entre el 500 a. C. y el 300 d. C. del horizonte bicromo en zonas expone ollas de borde grueso invertido e incisos anchos, pelotas de pastillaje y zonas de engobe en contraste con zonas sin engobar (Coe y Baudez 1961).

La introducción de más colores como negro, blanco y rojo abrió un abanico de estilos que emularon la pintura negativa Usulután de El Salvador, se introdujo la pintura con brocha múltiple, se dispararon las expresiones geométricas y estilísticas que combinaban pinturas, grabados precocción y modelados de figurillas tridimensionales (Baudez 1967, Abel-Vidor y otros 1990).

Durante el período Policromo Antiguo (500-800 d. C.) se desarrolló la policromía y el tipo Galo Policromo se parece a Ulúa Variedad Nebla de Honduras (Joyce 1993). Galo y Carrillo Policromo producidos en el sector sur casi no viajaron hacia el norte, sino que en ocasiones se exportan a otras partes de Costa Rica. Los tipos cerámicos, su composición, iconografía, distribución y consumo simbólico o ritual fueron de interés para ciertos grupos y élites políticas antiguas. Su estudio permitió a Ronald Bishop y Frederick Lange plantear escuelas alfareras en Gran Nicoya (Bishop y Lange 2013); un concepto relevante para distinguir la continuidad de grupos humanos en el territorio por medio de sus productos alfareros.

Alrededor de 800 d. C., se producen en Granada, Ometepe y Rivas en Nicaragua, cerámicas con engobe blanco y uso de moldes (técnica hondureña). Son los tipos policromos Papagayo, Pataky, Bramadero, Madeira y Vallejo Policromo. Aunque ocurren al momento de ingreso de grupos chorotegas, no tienen antecedentes en Mesoamérica sino que sugieren desarrollos propios en el sector norte. La icnografía a su vez, muestra vínculos con los mayas y posteriormente son relacionadas al estilo mixteca-puebla (McCafferty y Dennett 2014, Dennett y otros 2019). Sobresalen las representaciones de la serpiente emplumada, Tlaloc y Ehecatl. La centralización y estandarización de la producción refuerzan la propuesta 
de escuelas cerámicas.

También el sur produjo tipos específicos que emularon a los nicaragüenses, pero con engobes salmón o quemados (Baudez 1967). Destacan los tipos policromos Jicote, Mora, Santa Marta, Altiplano y Birmania. Se produjeron en el valle del río Tempisque y la península de Nicoya. También existió una producción alfarera con grabados y pastillajes. La cerámica de Nicoya tiene representaciones de chamanes y elementos animistas vinculados con la iconografía chibcha apreciable en jades, metalurgia y esculturas (Hoopes y Fonseca 2003).

\subsection{Pistas durante la colonia y república temprana}

La producción cerámica y la vida indígena cambiaron con la invasión de los españoles en el siglo XVI. La conquista de Nicoya ocurrió junto con Nicaragua, treinta años antes que el resto de Costa Rica. La lengua, así como las prácticas de sacrificio y antropofagia ritual observadas en 1529 en Nicoya, relacionan este pueblo y a sus vecinos con una identidad mesoamericana chorotega (Meléndez 1974a). Los españoles desarmaron el Concejo de Ancianos que existía y obligaron a los caciques a proveer esclavos para llevar a Perú y tributos en alimentos y mercaderías. Estos actos violentos junto con las enfermedades disminuyeron drásticamente la población. Los sobrevivientes fueron retenidos en las inmediaciones de la ciudad para ejercer mayor control (Sibaja y Zelaya 2015).

En esta etapa es difícil seguir la pista de la producción alfarera, sin embargo, hay datos que sugieren su continuidad. Nicoya fue un gran productor de algodón teñido de púrpura, así como miel, sal y alfarería, los que se obtendrían de pueblos cercanos como isla de Chira y las costas del golfo (Meléndez 1974a). En 1548, las tasaciones de López de Cerrato disponen la entrega de Nicoya de 300 cántaros con miel, e Isla de Chira 50 tinajas, ollas y mil piezas pequeñas de alfarería (Vega 1956: 402-404). En 1573 Juan López de Velazco anotó lo siguiente sobre isla de Chira: "hay en ella catorce indios casados, tributarios, y al pie de cuarenta mujeres, todos del Rey, que le tributan cuatrocientas piezas de loza, de que hacen gran cantidad, no con tornos, sino á mampuesto, alisándola sobre la mano con huesos de pescados" (cit. en Meléndez 1974a: 46).

Si existían entonces zonas de producción especializada, aun con una disminución de la población indígena y el mestizaje, permanecieron conocimientos antiguos como la cerámica para hacer utensilios de cocina en Nicoya y sus alrededores. El comal hasta entonces ausente del registro arqueológico debió difundirse con los españoles que ya habían conquistado México. Se trata de un plato cóncavo indispensable hoy en día en Guanacaste para cocinar la tortilla gruesa sobre un fuego de leña (Herrera 2004).

Carlos Meléndez (1974b) considera que la iglesia actual de Nicoya fue construida sobre el mismo lugar que ocupaba la plaza, templo y lugar de sacrificios del pueblo original. El primer templo se alzó entre 1524 y 1554; uno con tejas en 1644 y el templo actual en 1841. Las excavaciones arqueológicas como parte de su restauración reportan ocho recipientes cerámicos policromos precolombinos con indicios de restos quemados colocados como ofrenda en los cimientos del edificio (Camacho y Vargas 2017). Un depositario dentro del tempo con objetos quebrados datado en la primera mitad del siglo XIX contuvo cuatro ceramios en forma de comal con la superficie cubierta de curiol rojo y pintadas con curiol negro, cuya composición es similar a la procedente del cerro del curiol (Fernando Camacho, comunicación personal, febrero 2021).

\subsection{El pasado reciente}

El sitio arqueológico San Vicente localizado a 400 metros de la fuente actual de arcilla, sugiere que la zona estuvo poblada al final del periodo precolombino, pero no se sabe si hubo una ocupación continua hasta el presente. Al menos las generaciones de ceramistas nunca olvidaron la ubicación de las arcillas y curioles. La permanencia de la práctica alfarera apunta una cierta estabilidad de la vida rural y no inhibe la presencia de nuevos pobladores como fue el caso del repoblamiento a finales del siglo XIX, cuando personas de apellido Villafuerte establecieron un grupo de hogares centralizados en Guaitil. En cambio, personas de apellidos Grijalba y Acosta consiguieron propiedades grandes en San Vicente y otras familias tuvieron que ocupar barrios dispersos (Hernández y Marín 1975).

En 1914, el investigador Anastasio Alfaro visitó el barrio Chira, localizado a tres kilómetros al este de San Vicente y describió la confección de "cántaros y vasijas de barro, sin torno alguno, mostrando tal práctica y precisión en los contornos de sus manufacturas, que ponen de manifiesto la herencia indiscutible de los 
diestros alfareros precolombinos" (Alfaro 1914: 689).

A principio de la década 1950, Philip Wagner (1974) estudió la cultura campesina enfocada en la autosuficiencia, con jornales temporales en siembras de caña dentro de Guanacaste y de banano fuera de la zona. Wagner mencionó las comunidades alfareras de Guaitil, Sardinal, Belén, Santa Ana de Carrillo y Lagunilla de Santa Cruz, cuyos productos estuvieron presentes en las cocinas de la región. Además, cargamentos fueron llevados cada verano a los mercados de Puntarenas, el puerto principal del mar Pacífico, y a la Meseta Central, donde vivía la mayoría de la población costarricense.

Por la misma época, Doris Stone (1950) realizó un estudio etnográfico que permite apreciar la magnitud y organización del trabajo alfarero: en Guaitil, 21 hogares con 10 ceramistas, y en San Vicente, 42 hogares con 17 ceramistas. En todos los casos se trataba de mujeres que aprendían en sus propios hogares. Los hombres apoyaban las actividades secundarias como abastecer de arcilla, curiol y leña, así como ayudar en el transporte para la comercialización. Algunas alfareras contrataban peonas para que las ayudaran, pues la demanda tendía al incremento.

Si bien, para esa época la mayoría de los costarricenses se asentaban en el campo, los cambios ocurridos a partir de 1950 produjeron una disminución de la autosuficiencia rural y un desplazamiento del campo a la ciudad; la población de Costa Rica creció de 800.000 a 2.000 .000 entre 1950 y 1973 (Molina y Palmer 2007, Edelman 2005). Con el surgimiento de la sociedad consumidora en los años cincuenta, productos de fábricas industriales estaban apareciendo más disponibles. Es posible que la vajilla rústica, después de tantos siglos de su persistencia, hubiera podido desaparecer.

Sin embargo, la industria continuó y prosperó hasta el punto de que las iniciativas gubernamentales en infraestructura y programas sociales llegaron al campesinado. Se dieron intervenciones de parte de distintos agentes interesados en la producción alfarera. En 1965 el gobierno envió un asesor en cooperativas y en 1967 una voluntaria del Cuerpo de Paz de los Estados Unidos generó el apoyo de las familias y otros vecinos para crear la CoopeArte Chorotega de San Vicente y Guaitil. En este proyecto, como en otros después: "La historia de la transformación de idea a realidad en Guaitil es también la historia de influencias externas" (Shaw y Steinbauer 1973: 4).

La cooperativa fue liderada por Hortensia Briceño, quien logró relaciones colaborativas internas y externas. El taller colectivo en Guaitil transformó la organización de trabajo; las socias recibían salario y podrían especializarse en diferentes tareas según sus habilidades y preferencias. Algunas experimentaron con diferentes tamaños y formas poco tradicionales. Así se dio un acercamiento a los diseños precolombinos, promovido en parte por fotos de piezas arqueológicas que entregó la entonces primera dama del país. A pesar de que el proceso de manufactura era el mismo descrito por Stone, entre diversos cambios los camiones sustituyeron las carretas con bueyes para transportar el barro y las mercancías; las formas tradicionales disminuyeron para dar paso a un mercado interesado en artes étnicas y de recuerdo (Shaw y Steinbauer 1973, Howard 1979). 


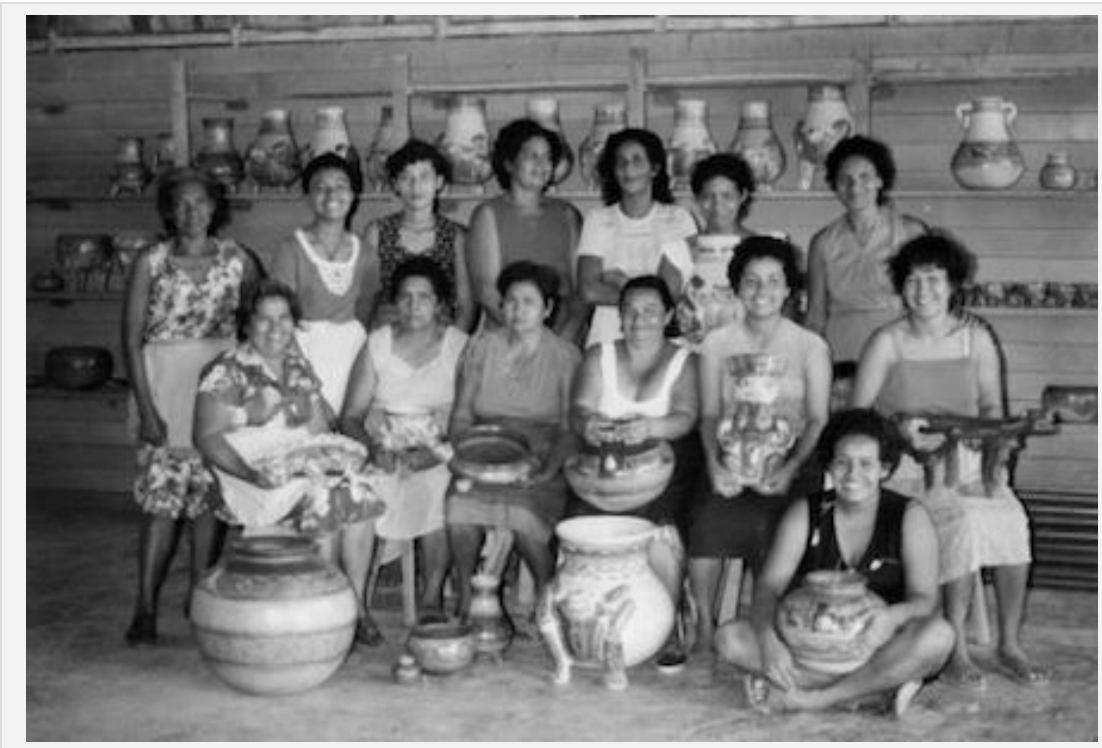

Socias de la CoopeArte Chorotega mostrando sus creaciones alrededor de 1980. Foto cortesía de Hortensia Briceño.

La directora Hortensia Briceño se retiró 1983; un año después la cooperativa se disolvió y las alfareras regresaron a hacer la cerámica en sus casas. Las tareas en el hogar no habían cambiado; ellas debían empezar el día más temprano para completar labores hogareñas y al regreso proseguir con los oficios domésticos (Shaw y Steinbauer 1973). Los hombres no tenían que cumplir con tareas domésticas y su labor en agricultura, ganadería o construcción estacional les dejó con tiempo para el trabajo alfarero (Hopper 1994). En 1984, un grupo de hombres constituyó su propia Cooperativa de Cerámica Chorotega. La mayoría fueron de San Vicente y se interesaron en la producción de réplicas arqueológicas. Las destrezas propias para pintar y la libertad para experimentar en su papel como alfareros les permitieron conseguir réplicas más exactas. Así se introdujo el rol, un instrumento ideado localmente que emulaba la rueda de alfarero, pero sin cumplir con la función de torneado. El taller de hombres recibió roles importados; otros artesanos obtuvieron roles hechos por mecánicos locales utilizando partes desechadas de motocicletas. Ellos adquirieron la técnica del uso de moldes e incrementaron el número de personas dedicadas a esta artesanía en ambas comunidades. Según Hortensia Briceño (comunicación personal, 2018), la cooperativa de mujeres rechazó el uso del rol para guardar lo que entendían como la tradición auténtica.

En la década de 1990, las continuas recesiones económicas y giros a nivel mundial orientados al neoliberalismo afectaron el apoyo gubernamental y varias agencias, nacionales e internacionales se hicieron más presentes. Sin cooperativas, los artesanos, hombres y mujeres establecieron sus talleres como negocios particulares.

En 1992, otro voluntario del Cuerpo de Paz plantó la idea de un ecomuseo para San Vicente que buscaba preservar la herencia cultural y natural, pero sobre todo atraer visitantes para comprar cerámica. En 1995 el Poder Ejecutivo emitió un decreto de creación del Ecomuseo (Decreto C-25547). La reducción del presupuesto nacional impidió el desembolsó de los fondos prometidos. Igual a la cooperativa de mujeres, el museo nunca habría superado los obstáculos y demoras sin liderazgo carismático. Maribel Sánchez Grijalba impulsó el Comité Pro-Ecomuseo a conseguir, con la ayuda de voluntarios norteamericanos, una beca de parte de la Fundación Interamericana en 2001 para la construcción. No recibieron los fondos hasta 2004, cuando se constituyó una asociación legal. En 2007 con los edificios casi completos se inauguró el Ecomuseo de la Cerámica Chorotega.

La industria alfarera de Nicoya llegó al fin del siglo XX con características distintivas a otras del país o de Nicaragua, país donde además de la vajilla utilitaria, la artesanía desarrolló un estilo moderno con reconocimiento mundial. Desde hace un par de décadas es un fuerte competidor en el mercado turístico costarricense. 
Hasta el siglo XXI, la historia de la tradición alfarera de Nicoya sugiere pautas de cambio a largo, mediano y corto plazo por acción directa de los artesanos y los agentes externos.

\subsection{El proceso de producción}

Esta es una mirada actualizada del proceso de manufactura alfarera (Stone 1950, Shaw y Steinbauer 1973, Howard 1979, Hopper 1994, Herrera 200, González y Zamora 2002, Weil y Herrera 2014).

\section{Materias primas}

La arcilla principal proviene del yacimiento localizado en San Vicente. Es de color gris, permite crear formas complejas y recibe el curiol. La fuente de Guaitil es rojiza y solo sirve para elaborar recipientes para cocinar, pues no se le puede poner curiol. La arcilla se suele mezclar con arena fina gris en depósitos geológicos a profundidad visibles en los nidos de iguana, de ahí su nombre arena de iguana (Guadamuz 2019).

Los curioles o colores tradicionales blanco y rojo son de origen mineral y aparecen juntos en el cerro con su nombre. Se deben moler y remojar en agua para lograr una textura acuosa; se usaban metates o losas volcánicas, a menudo antiguas. Ahora se trituran en la máquina manual para moler maíz. El curiol rojo aparece en pequeños nódulos muy duros llamados muñequitas mientras que el blanco es suave. Para extraer el curiol o la arcilla se siguieron pautas de comportamiento relacionadas con el silencio y la fase lunar; hoy día es menos estricto.

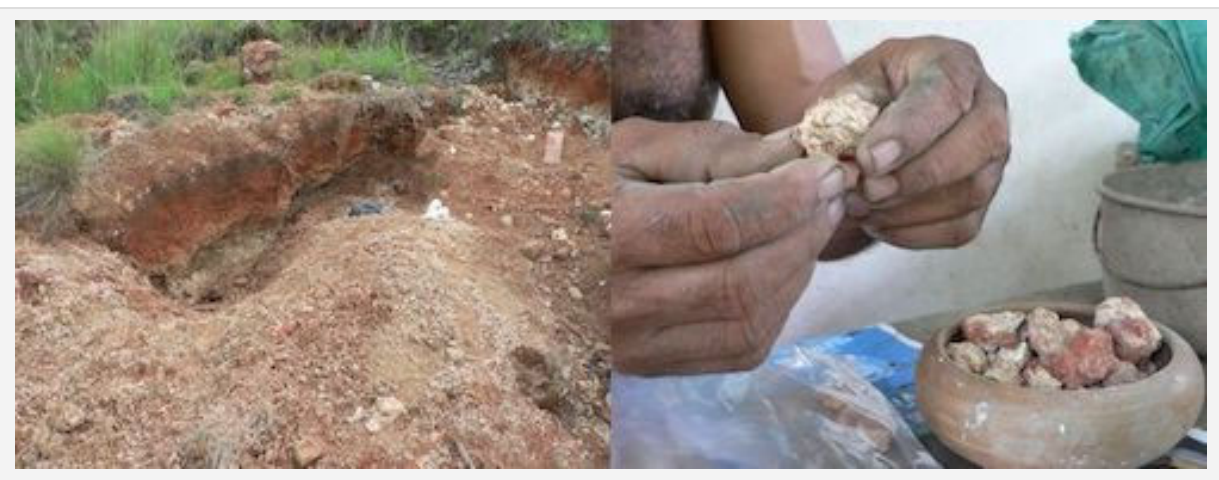

Lugar de extracción del curiol. Luciano Grijalba sostiene muñequitas de curiol rojo.

El curiol negro se obtenía en las cercanías de Santa Bárbara, camino a Bernabela. En la actualidad se trae de Santa Rosa (Lagunilla). El primero más fino y oscuro aparecía como hilos o cascaritas mescladas con cascajo, mientras que el segundo aparece como arena y requiere cuidado al secarse y alujarse.

Últimamente se han introducido pinturas industriales. Los colores van de tonos amarillos a azules, pero domina el verde. Para facilitar la adhesión de estos pigmentos se mezclan con curiol blanco; su aplicación demanda una mayor atención. 


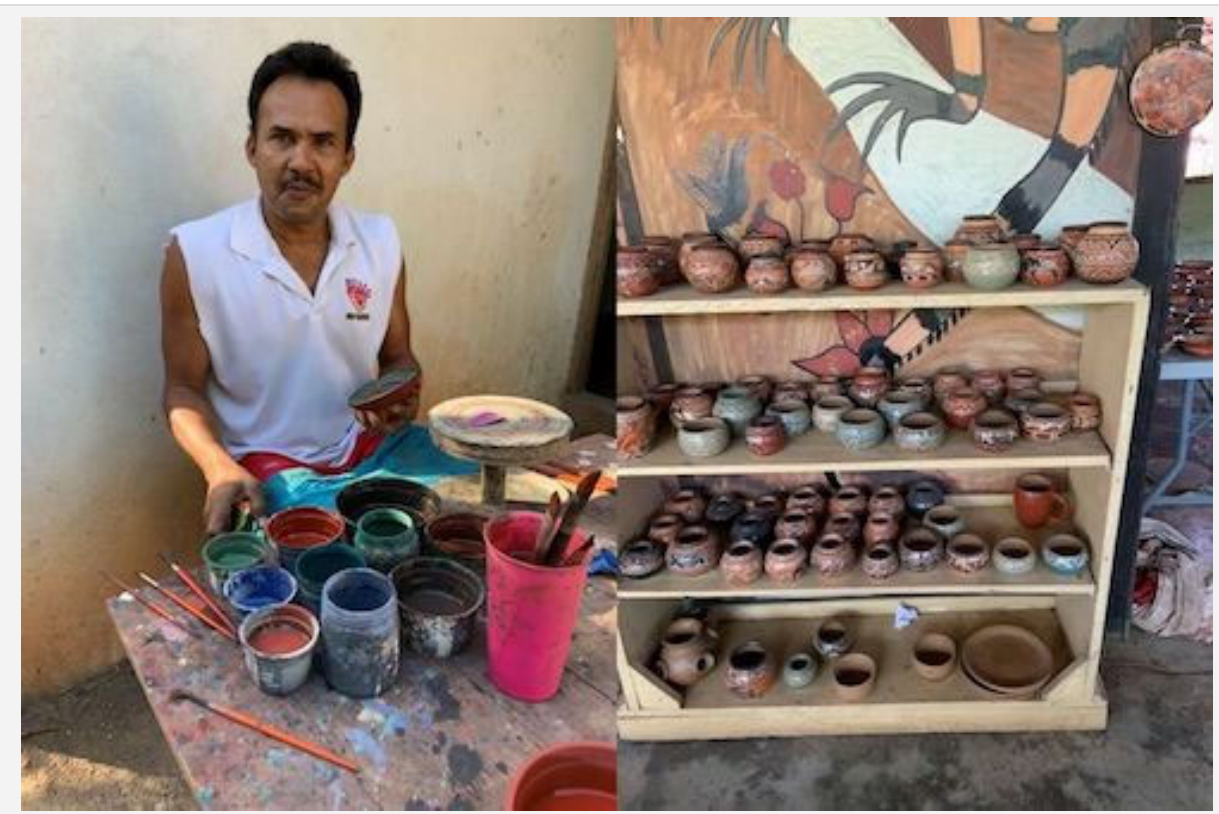

Francis Dimas Chavarría muestra las pinturas industriales y naturales (curioles) que usa. Al lado, piezas de Guaitil pintadas con esos mismos colores.

\section{Preparación del barro}

La arcilla se pudre en agua por varios días antes de mezclarse con la arena de iguana (dos partes por una). Hasta la década de 1960, las impurezas se extraían con la mano durante el amasado, luego se introdujo el pilón de madera para moler la arcilla seca, que luego se tamiza en una zaranda fina. Se mezcla con los pies en el suelo sobre un plástico o cobertor grande, colocando agua hasta lograr una textura plástica. El sobrante se conserva tapado con plástico negro. Este pateado lo solían hacer los niños; así empezó la mayor parte de los artesanos. Las mujeres deben evitar el barro durante el periodo menstrual porque este es muy frío (Stone 1950: 272, cf. Freire 2017).

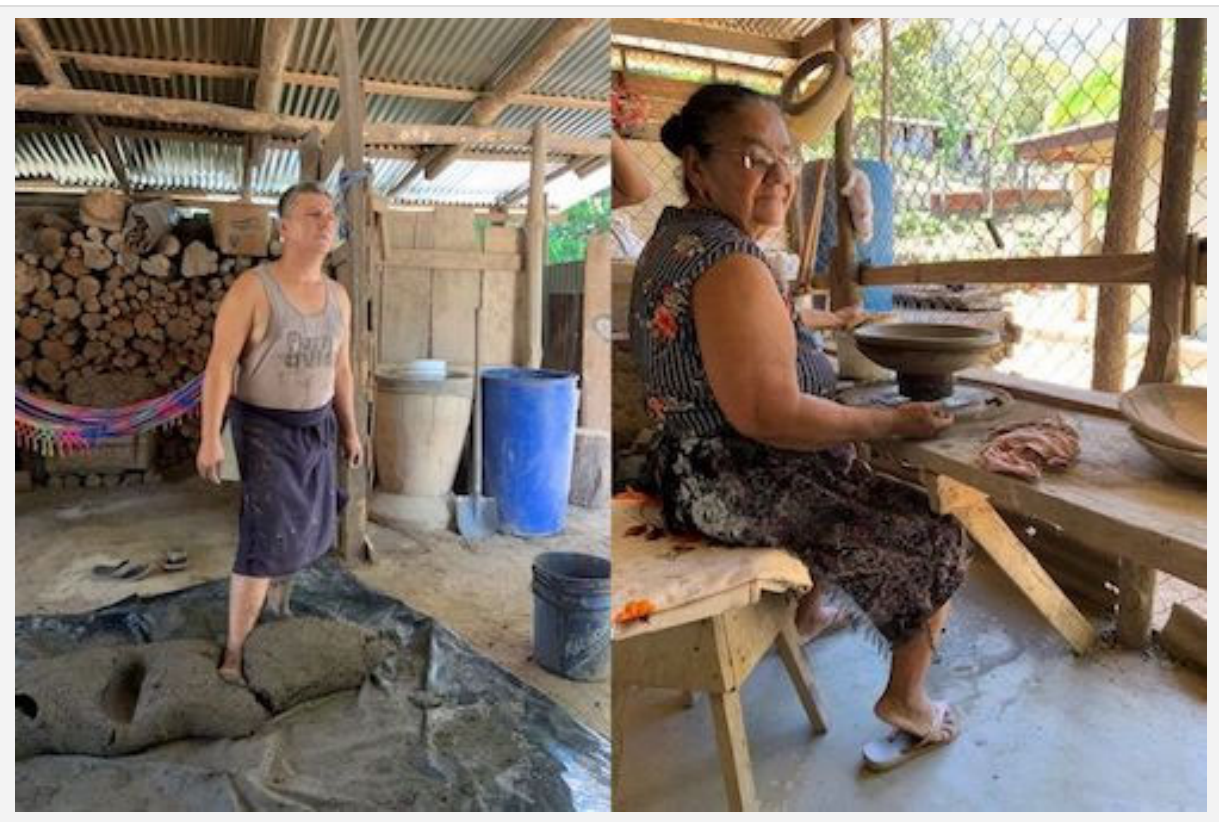

Gredy Chavarría patea el barro; atrás, el pilón. Tomasa Grijalba realiza un comal sobre molde y rol. 
Generalmente se hace una tortilla de barro y se pasa a un molde en forma de comal, al cual se le ha puesto arena. A partir de allí se colocan rollos gruesos de arcilla de hasta tres centímetros de diámetro unos sobre otros, al mismo tiempo que se unen con los dedos y con un olote (corazón de la mazorca de maíz). También se emplean cucharas de jícara (calabaza de árbol Crescentia alata) o de plástico para emparejar y retirar el barro extra. Cuando el recipiente está acabado se desprende del molde y es necesario dejarla orearse antes de descarnar el exceso de arcilla. Para eso se usa un cuchillo de metal.

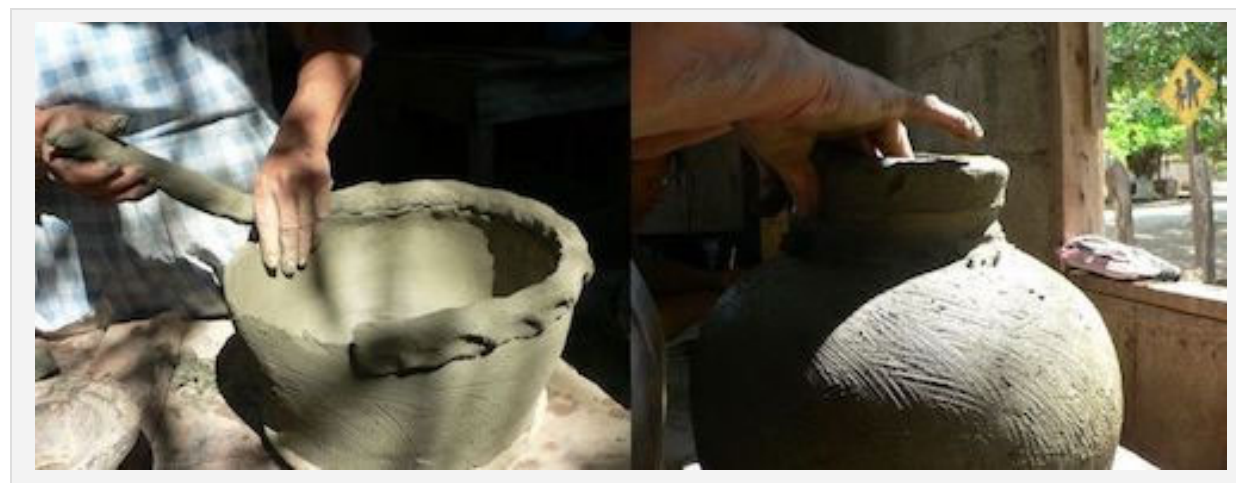

Zoraida Grijalba en 2006 coloca rollos y el gollete de una tinaja. Las huellas son de olote.

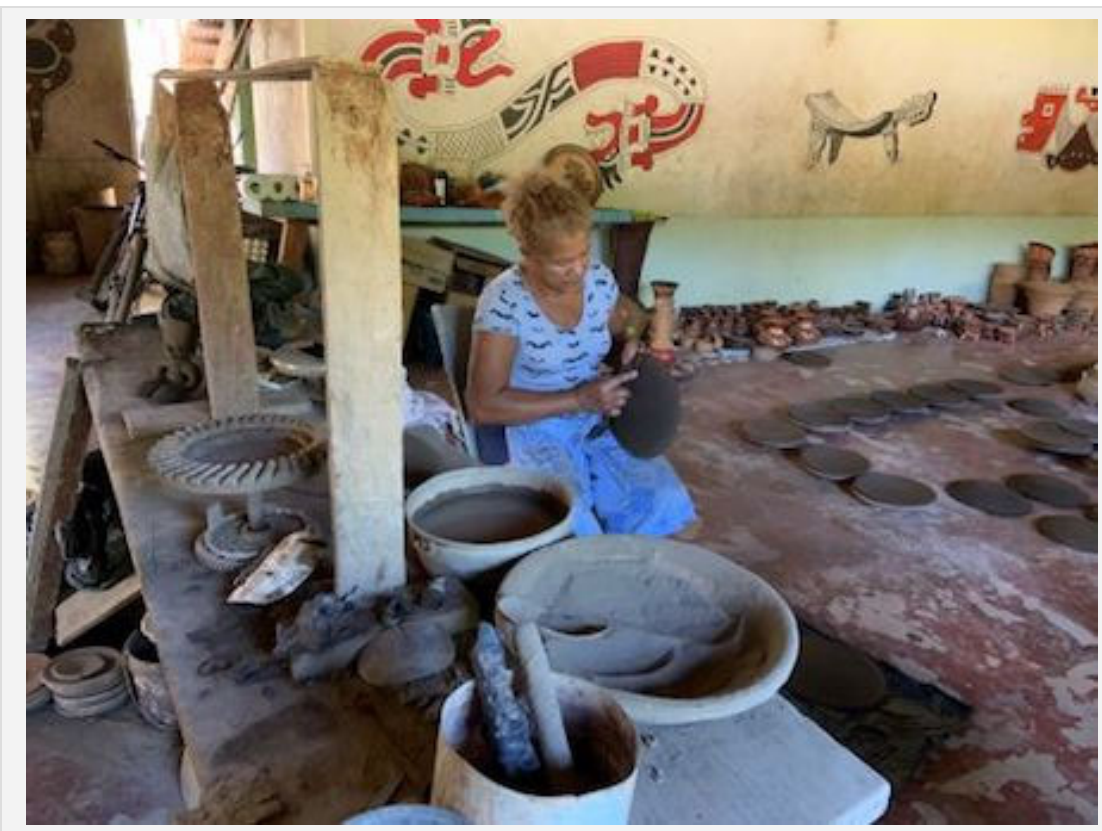

Ilsia Chvarria descarna un comal.

Nótese el rol, codal, arena de iguana, olote y comales oreándose.

La técnica de presión se emplea en piezas pequeñas; una pelota de barro se golpea con el puño para dar profundidad y se levanta con la ayuda de los dedos. Los moldes se usan en la elaboración de los soportes y cabezas de jaguar de las réplicas precolombinas.

El rol sirve para elevar la altura de las piezas, facilitar su confección y aplicar la pintura con pincel. Se impulsa con una mano mientras se trabaja con la otra. Como complemento, se emplea un codal que es una estructura de madera y sirve para apoyar la mano o el brazo mientras se pinta líneas circunferenciales.

Las superficies de los recipientes se han trabajado con hojas de guayaba, cuero y piedras redondeadas de cuarzo llamadas sukia. A menudo heredadas que fueron extraídas de tumbas indígenas. Algunas personas les tienen un nombre. La piedra ayuda a asentar la superficie y deja huellas características durante el alujado. Cada vez son más populares las paletas de plástico, pues el acabado es más parejo y requiere menos tiempo. En Guaitil se observó el uso de bolsas plásticas con el mismo propósito. 


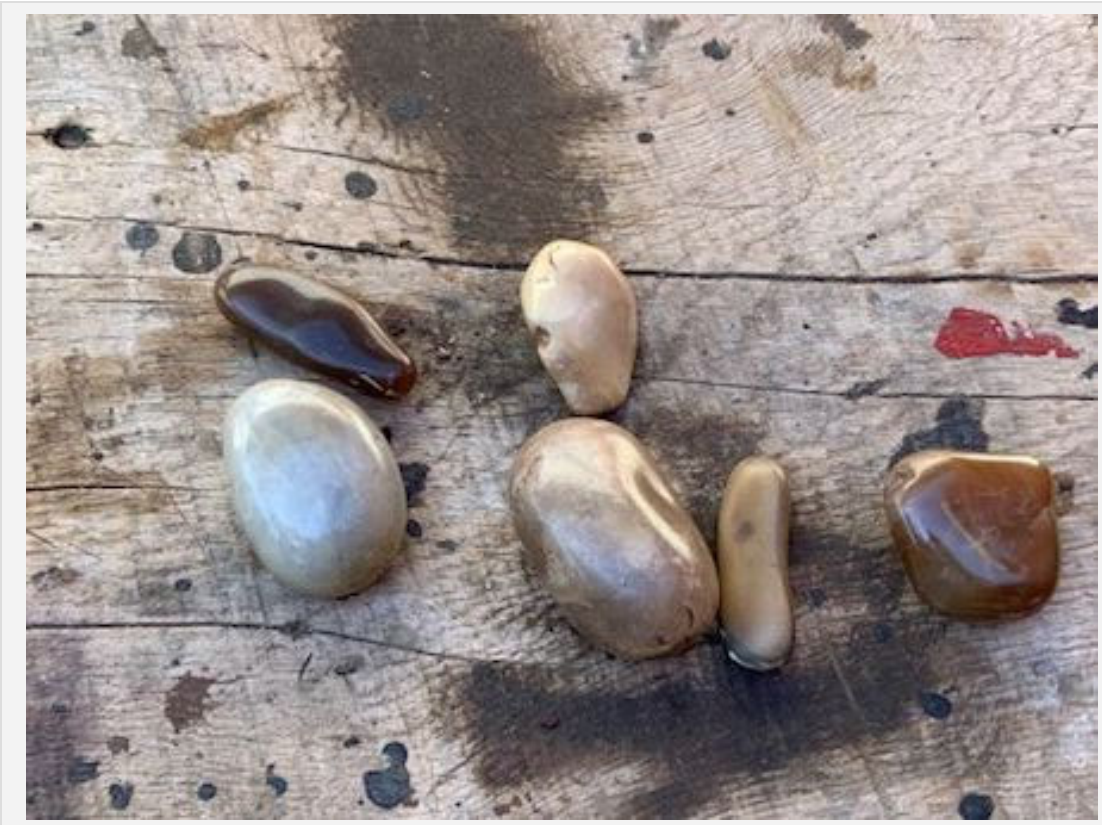

Piedras sukias para asentar y alujar, propiedad de Marta Espinoza.

Las superficies pueden llevar curioles. Su aplicación se hacía con una tela de algodón, hasta cuatro capas; hoy se emplea una brocha industrial. La pieza debe asentarse para que el curiol no se desprenda. El acabado negro se logra con curiol negro o ahumando la pieza.

Las primeras alfareras usaban la pluma interior del ala de la gallina para pintar, ahora solo se usan pinceles. A menudo, cuando la superficie aún está húmeda, se calan o graban líneas y áreas en los diseños pintados con un punto metálico al fin de un palito. El alujado final se ejecuta cuando la pieza está en dureza de cuero y ya ha sido pintada. En Guaitil se observaron piezas decorativas acabadas con tinte de zapatos y cera de pisos para dar colores y brillos diferenciados.

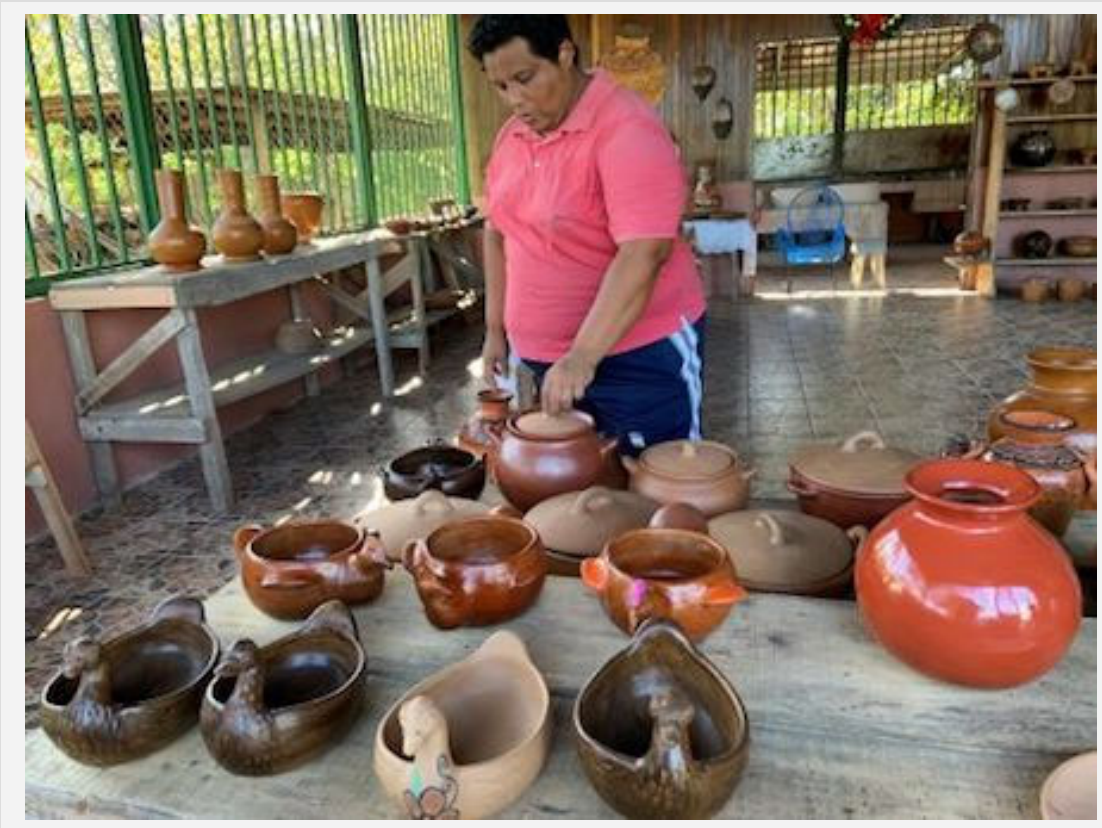

Derix Briceño muestra piezas con tintes y ceras en Guaitil.

\section{Secado y quemado}

Debido a que el clima es cálido, el secado rápido debe evitarse. Antes de quemar las piezas se secan al sol por uno o dos días. Los hornos antiguos eran cavidades excavadas en el suelo o en paredones protegidos con cobertores. Los hornos de barro se introdujeron en la colonia para asar pan y se 
adoptaron para la cerámica. Consisten en una armadura arqueada de bejuco o metal rellenos de arcilla, tierra, boñiga y pasto, de ahí su nombre de bóveda o colmena.

Los hornos tienen máximo tres aberturas para introducir la leña y las piezas. La leña se quema para lograr la temperatura alrededor de $600{ }^{\circ} \mathrm{C}$. Luego se insertan las piezas empleando una horqueta de metal con una terminación doble. Las piezas deben quemarse a buen fuego por una hora.

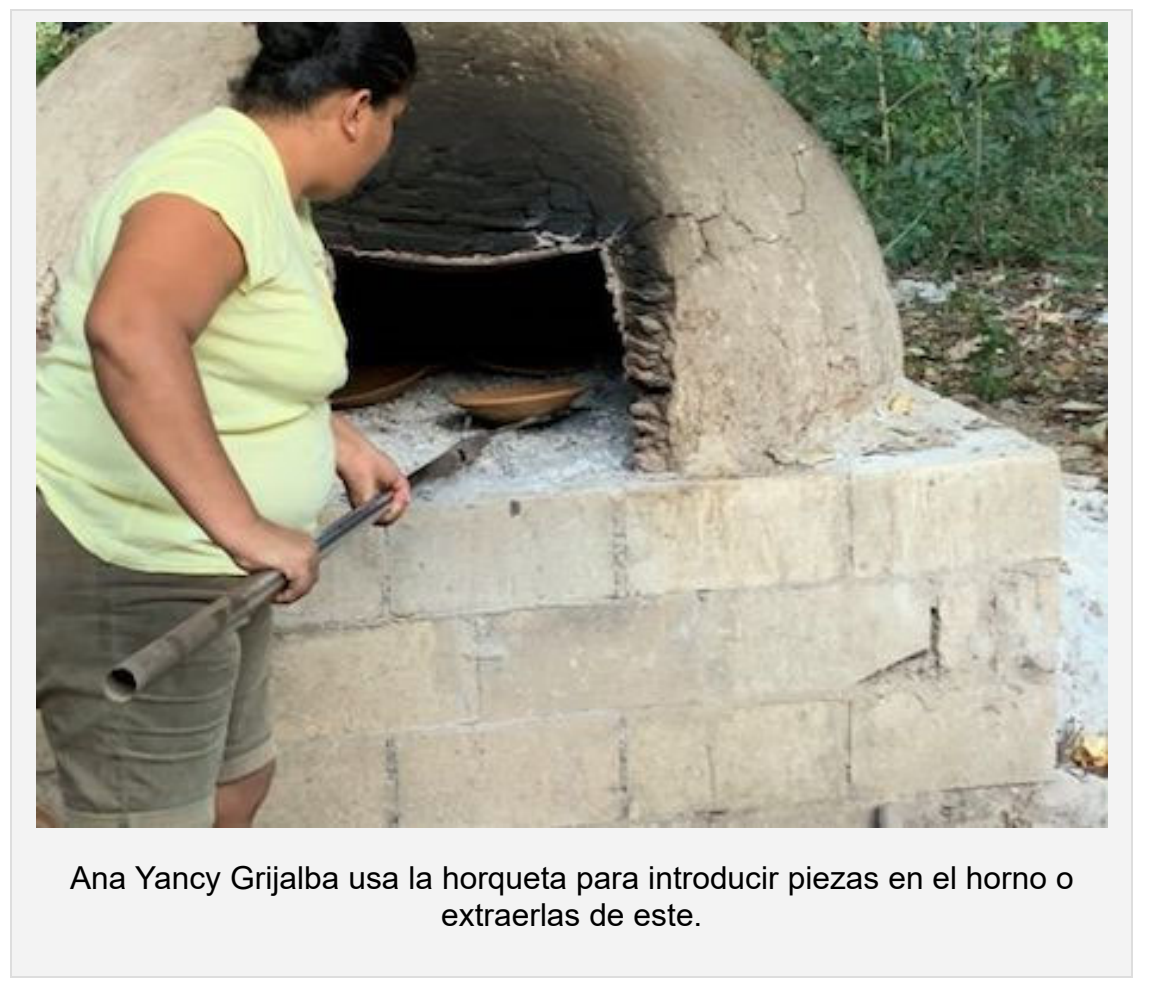

\section{Organización de trabajo}

Hasta la segunda mitad del siglo pasado las mujeres confeccionaron la cerámica en la cocina o afuera de la casa, siempre en el suelo sobre la tierra directamente, aunque con ayuda de un soporte en forma de comal. A la hora de secar las piezas las colocaban sobre una tabla o un cuero para evitar daños por la humedad. Con el taller de mujeres como modelo, las familias artesanas empezaron a construir edificios 0 al menos espacios bajo techo para hacer la cerámica. Desde el fin de la época de cooperativas en el nuevo siglo XXI, los talleres particulares han adoptado las mismas formas de organización. Utilizan una división de las tareas entre trabajadores pagados y tienen espacios para vender los productos. 


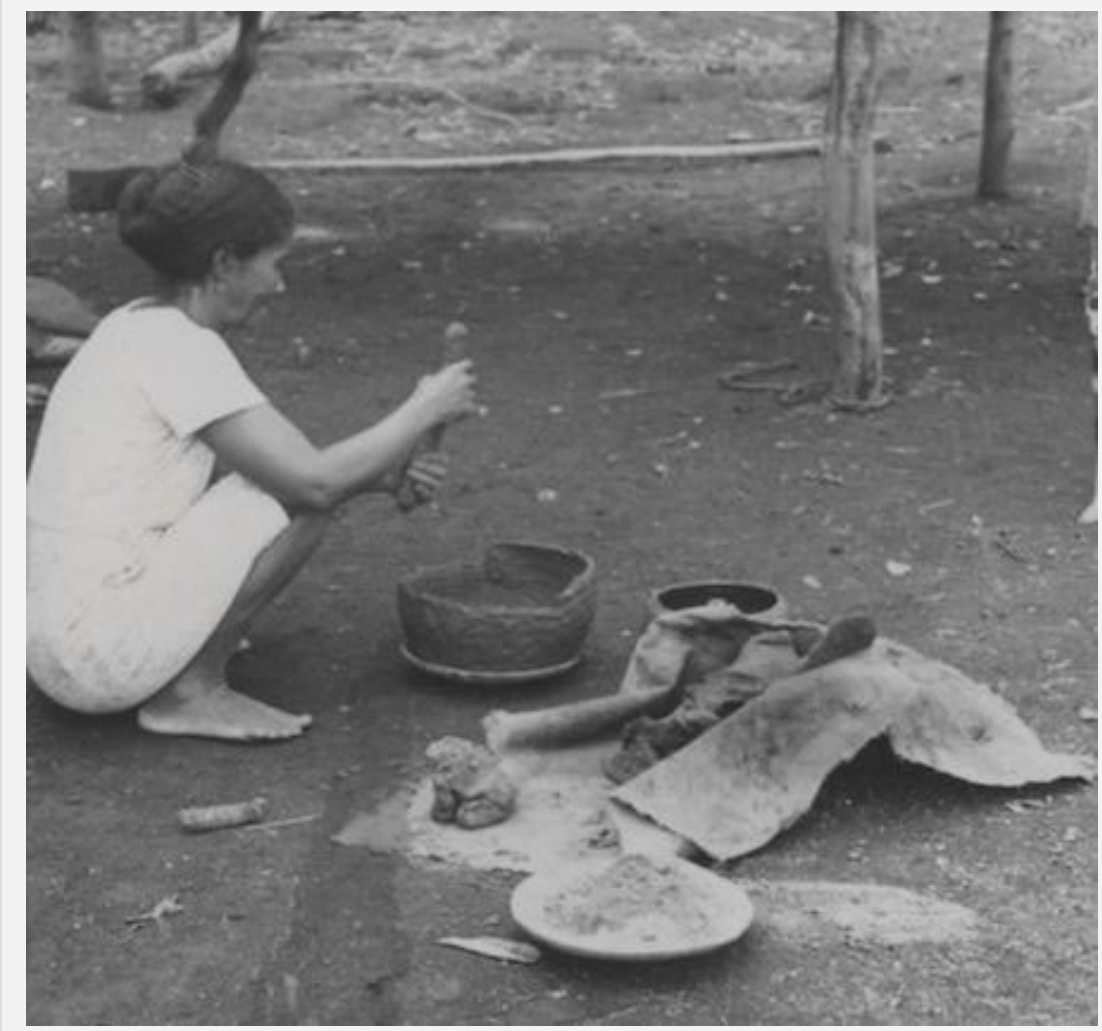

Teodorica Villafuerte trabaja afuera de su casa en el suelo, la norma hasta la segunda mitad del siglo XX. Stone 1950: 274. Reproducido por cortesía del Middle American Research Institute, Tulane University).

Los cambios recientes no solo son de género, sino también de edad porque las nuevas generaciones están más dispuestas a innovar. Algunos artesanos tienen habilidades para desempeñar todo el proceso, así como la habilidad para levantar piezas de distintas características. Los ayudantes contribuyen en labores que requieren menos destrezas y menos concentración. Los artistas poseen habilidades creativas y técnicas sobresalientes; pueden trabajar solos, participar en la confección de piezas complejas o pintar diseños detallados en piezas hechas por otros (Weil 2010).

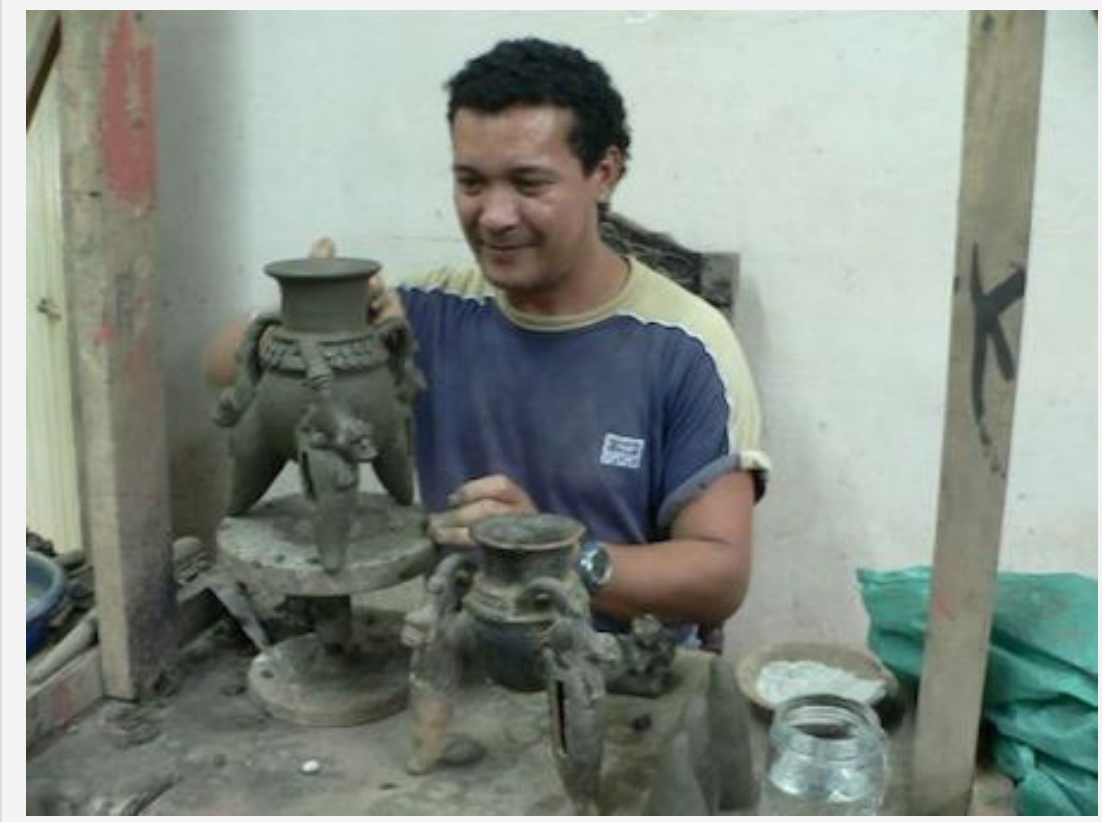

Elpidio Chavarría realiza una réplica de pieza precolombina.

Varios factores se conjugaron en las décadas recientes alrededor del neoliberalismo, con diversas consecuencias. Además, se dieron capacitaciones técnicas de parte de instituciones estatales. Todas ellas favorecieron un aumento de la participación masculina en la alfarería, innovaciones técnicas y, por 
consiguiente, una mayor presión sobre las fuentes de materias primas. Un censo realizado en 2010 arrojó 74 talleres artesanales en San Vicente y Guaitil entre los que figuraban 165 personas involucradas en las tareas entre 11 y 89 años, de los cuales 99 eran masculinas y 66 femeninas. Las mujeres jóvenes participan a nivel reducido porque además de sus estudios, todavía deben colaborar en las tareas domésticas (Rubí y Rueda 2011).

\subsection{Modalidades del comercio}

\section{Ceramistas y estilos}

La mayoría de la cerámica producida muestra un estilo híbrido, pintado y muchas veces calado con diseños inspirados en los antiguos. Hay piezas decorativas con iconografía que representa animales de la cosmología indígena en forma abstracta y líneas como escalones o trenzas que recorren la circunferencia de vasijas y platones; se denominan motivos chorotegas. Otras piezas representan la fauna y flora más naturalista; se llaman motivos ecológicos. Este grupo, con líneas más sencillas, ha sido el estilo dominante desde los principios del siglo XXI.

La cerámica lleva capas de curiol rojo, blanco o negro, con diseños pintados en colores contrastantes. La hibridación aparece también en la combinación de formas, algunas derivadas de la vajilla doméstica y otras inspiradas por piezas arqueológicas. Sin embargo, persiste la producción de piezas tradicionales con fines domésticos.

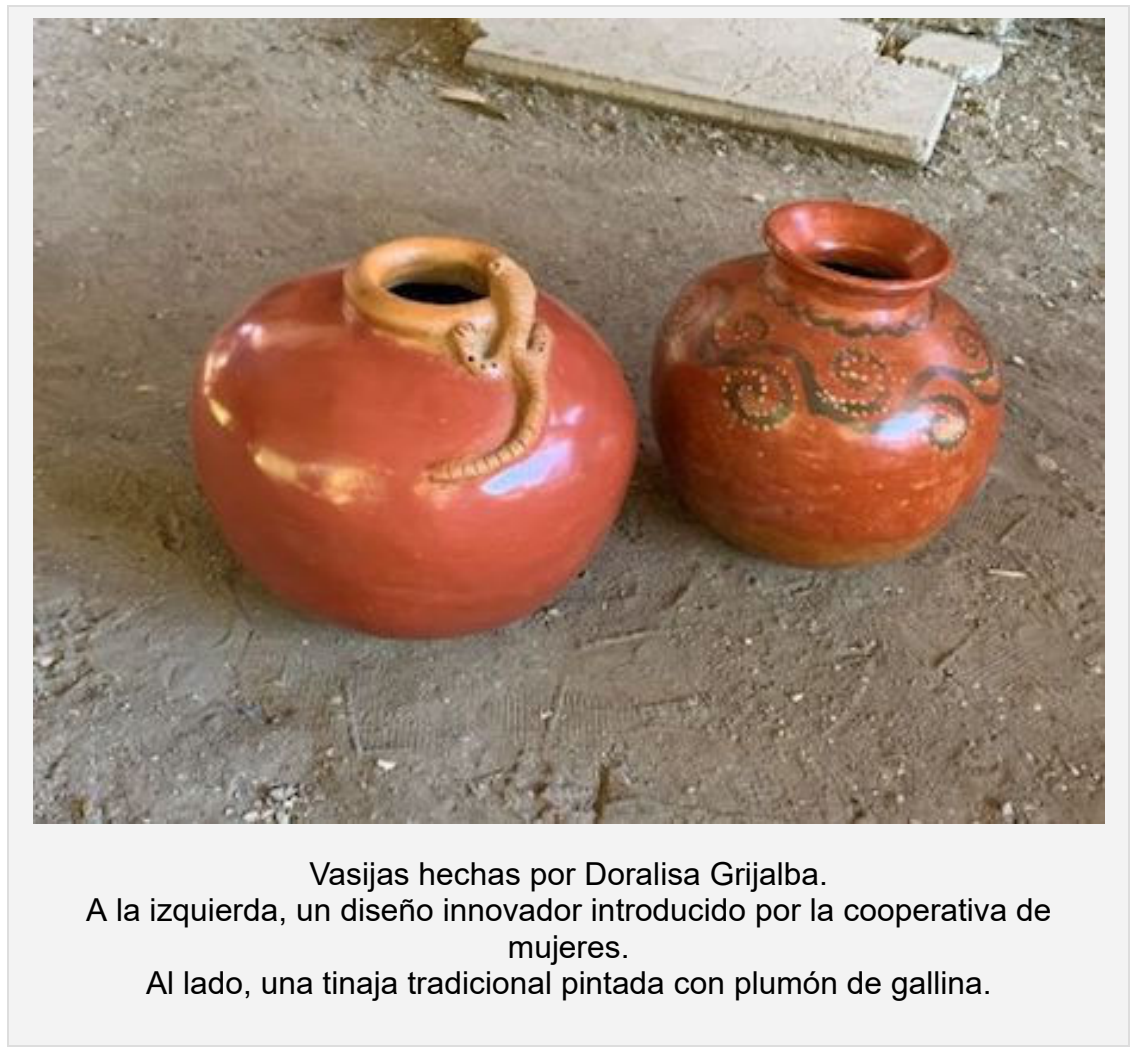

Hasta los años 1980, las artesanas de CoopeArte seguían confeccionando esta cerámica, pero las ceramistas más creativas empezaron a adornar estas piezas y experimentar con las formas y acabados de los estilos ancestrales. Patricia Howard (1979: 21-22) observó que habían surgido tres grupos estilísticos: el estilo tradicional de piezas utilitarias sin adorno; el estilo moderno con formas y acabados más complejos; posteriormente, las socias introdujeron formas más grandes y mezclas, incluso empezaron a reproducir las piezas arqueológicas. Este tercer grupo, identificado por Howard como estilo indio estaba en estado preliminar.

Fue entonces cuando mujeres y hombres experimentaron las técnicas precolombinas. Creció un grupo de ceramistas capaces de plasmar obras muy exactas. Aprendieron a pintar los detallados diseños abstractos propios de la herencia alfarera de Gran Nicoya; es apto llamar estas piezas antigüedades virtuales (Weil 2004). Los talleres produjeron una gran variedad de ellas, algunas piezas completas o con detalles exactos. 


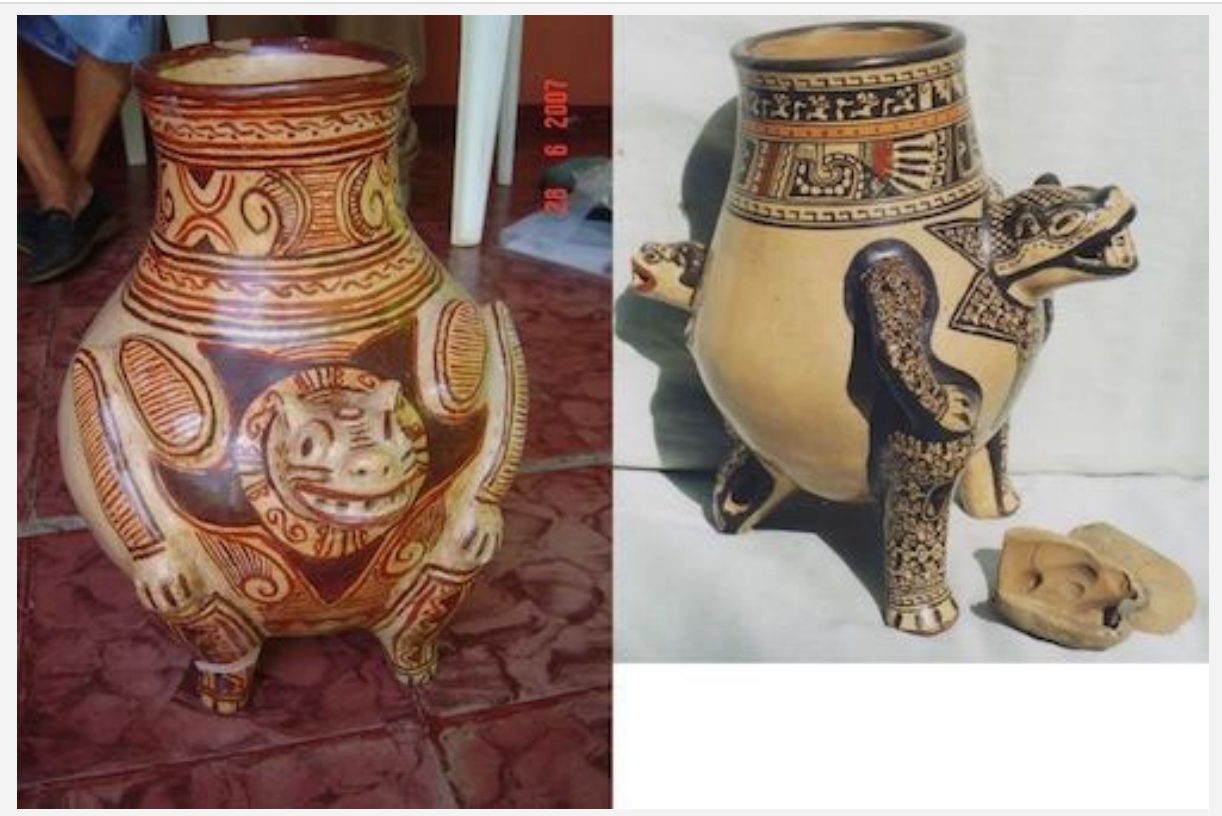

Aproximación temprana a pieza precolombina hecha por Hortensia Briceño en CoopeArte Chortega. Réplica hecha por Carlos Grijalba en 2005 con molde de cabeza.

En la década de 1990 surgieron los temas de la naturaleza inspirados en diseños precolombinos, pero plasmados de forma más realista Por medio de sus compras los turistas extranjeros expresaron esa preferencia. A la vez aparecieron técnicas para decorar las capas de un solo color con otro color encima, minúsculas salpicaduras aplicadas con un cepillo de dientes o manchas aplicados con una esponja. Otro cambio significativo fue la transformación del comal en colgante. Mientras que los comales tenían casi exactamente el mismo diámetro, los colgantes podrían tener tamaños disímiles.

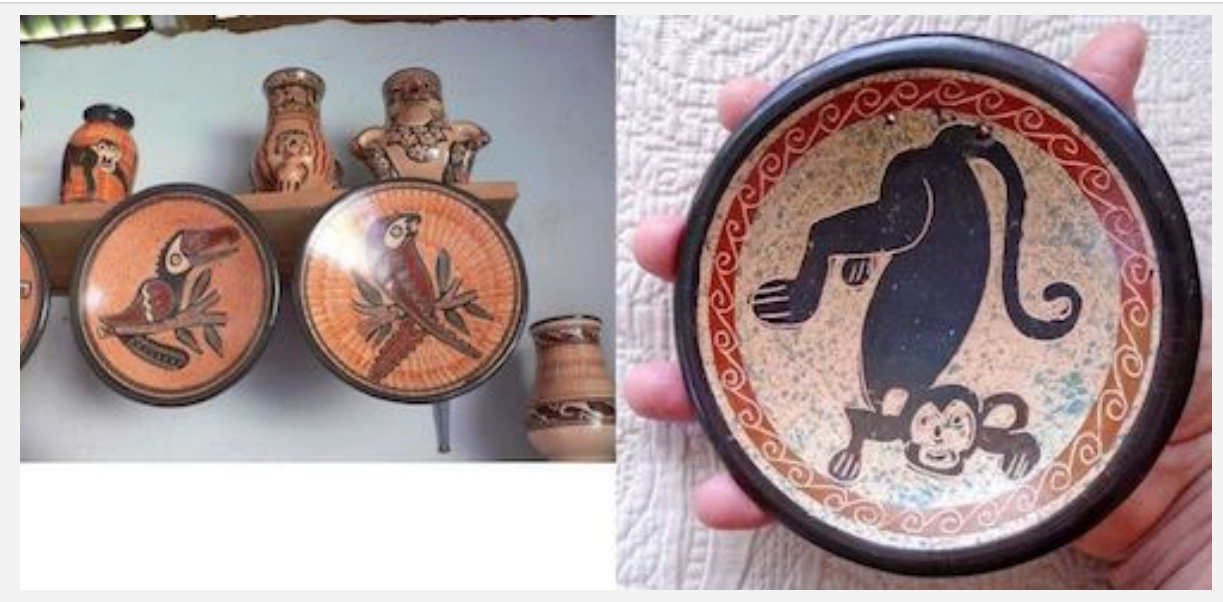

Motivos ecológicos sobre colgantes. Nótese las manchas en las piezas a la izquierda y las salpicaduras en la pieza a la derecha.

De largo plazo, la proporción de piezas pequeñas y semejantes creció, mientras las creaciones complejas e individualizadas declinaron. El número de artesanos aumentó, pero pocos con destrezas avanzadas. Muchos artesanos respetados con clara capacidad artística encontraron cada vez menos compradores. El éxito y persistencia de la alfarería se basa en la capacidad de innovar nuevos productos, diversificar los mercados y participar de espacios virtuales en plataformas de internet. La diversificación de estilos ha permitido la persistencia de la herencia artesanal, a través de la adaptación a las preferencias del público. 


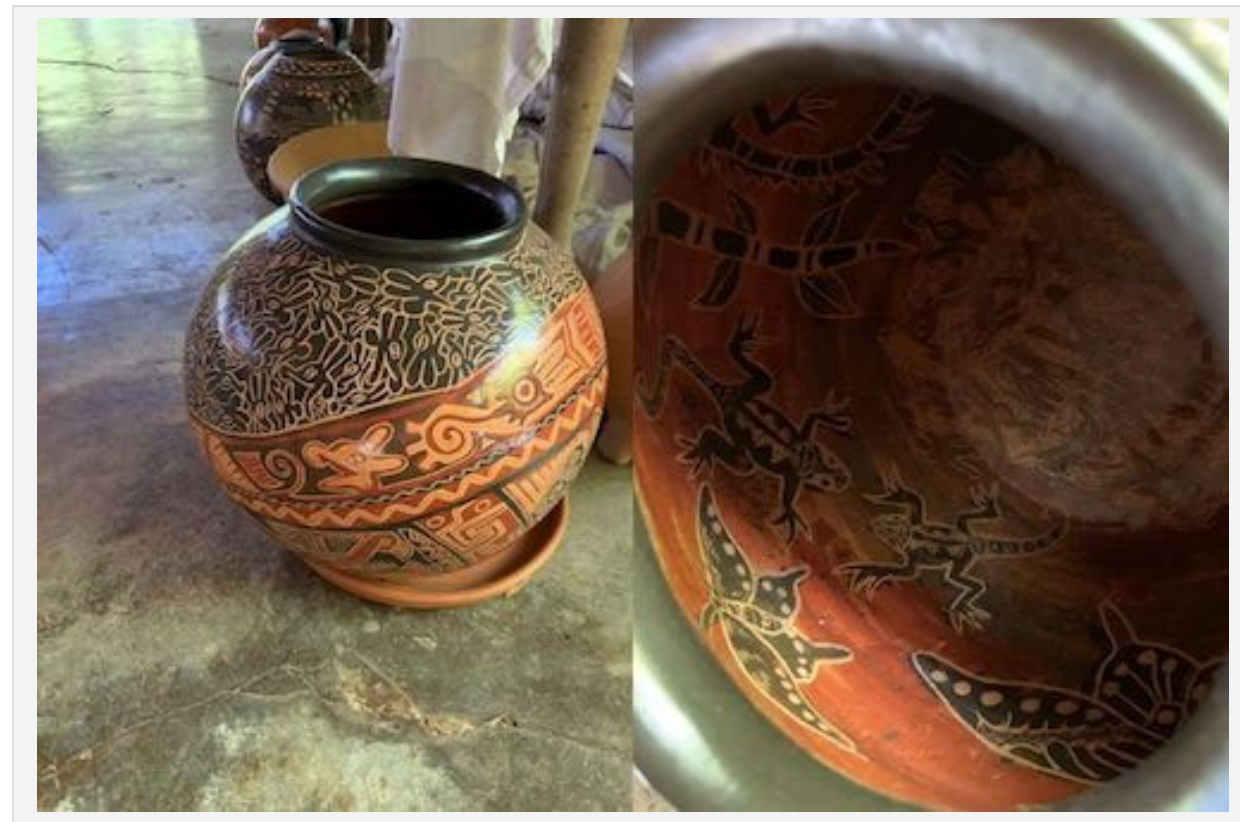

Pieza híbrida que combina motivos chorotegas y ecológicos en una composición y un diseño innovador.

\section{Consumidores y mercados}

El mercado de piezas pequeñas o tradicionales tiene un lugar en tiendas de todo el país o en puestos al lado de las carreteras. Piezas de excelencia técnica y estética están menos disponibles. Algunos turistas compraron directamente en los talleres donde lograron un encuentro personal y adquirieron buenas réplicas u obras creativas. Otro grupo de turistas buscaron piezas para autenticar sus experiencias como ecoturistas. Sin embargo, miembros de un tercer grupo más grande nunca llegaron a visitar las comunidades. Son la mayoría de los turistas que pasan todo su tiempo en la playa u otro lugar de ocio. Les interesan más los suvenires baratos y no les importan tanto los valores culturales.

Los talleres venden la mayoría de sus piezas en lotes a intermediarios para tiendas saturadas. Si es que llegan a las comunidades, los turistas lo hacen a Guaitil porque su ubicación ha potenciado los encuentros, mientras que San Vicente dos kilómetros más allá, aun con su Ecomuseo, recibe un mínimo de visitantes.

Llegan los consumidores nacionales que buscan la cerámica tradicional por su valor nostálgico o para cocinar comidas en la manera de sus abuelos. Es probable que se compren también las piezas con motivos chorotegas y motivos ecológicos. Durante de la pandemia de 2020-2021, a falta de turistas extranjeros, los turistas nacionales hicieron encargos especiales de piezas tradicionales.

\subsection{Las organizaciones y sus desafíos}

Uno de los magnos desafíos de la tradición alfarera ha sido asegurar las materias primas. Diversos factores han actuado para que, tras más de siete décadas, los artesanos no tengan seguro el acceso a la arcilla. Si bien se contaba con una parcela a nombre de la Municipalidad de Nicoya que brindaba acceso a los artesanos, nuevas titulaciones oscurecidas por la falta de documentación inhiben a las comunidades del acceso libre a estas fuentes (Chang 2016). Con el propósito de trabajar en este tema y otros, se creó en 2008 la Cooperativa de Comercialización de los Productores de Cerámica Chorotega de San Vicente de Nicoya y Guaitil de Santa Cruz R. L., siglas CoopeSanGuai.

Una petición de ayuda de parte de CoopeSanGuai y del Ecomuseo originó en 2013 una reunión mixta con participación de instituciones, municipalidades y el propietario para negociar la compra de la propiedad. La reunión derivó en la declaratoria de interés público de la tradición artesanal incluyendo la extracción de las materias primas y su elaboración, así como la declaración de patrimonio cultural intangible (Decretos N $N^{\circ} 37823-C$ y 37824-C), pero la compra de la propiedad no se realizó (Chang 2016). Las universidades estatales emprendieron colaboraciones, entre ellas la búsqueda de fuentes de arcilla 
alternativas. En la actualidad se han detectado tres yacimientos potenciales (Guadamuz 2019).

Otro de los grandes desafíos es la comercialización justa de los productos. Aunque desde el año 2000 Costa Rica había aprobado una ley de marcas y signos distintivos de la propiedad intelectual, fue hasta 2017 que se registró de forma oficial el sello de denominación de origen para la cerámica chrorotega. Los artesanos dirigidos por CoopeSanGuai y con asesoría de la Universidad de Costa Rica y la Universidad Nacional definieron los signos y se inició la formación para la adquisición del sello.

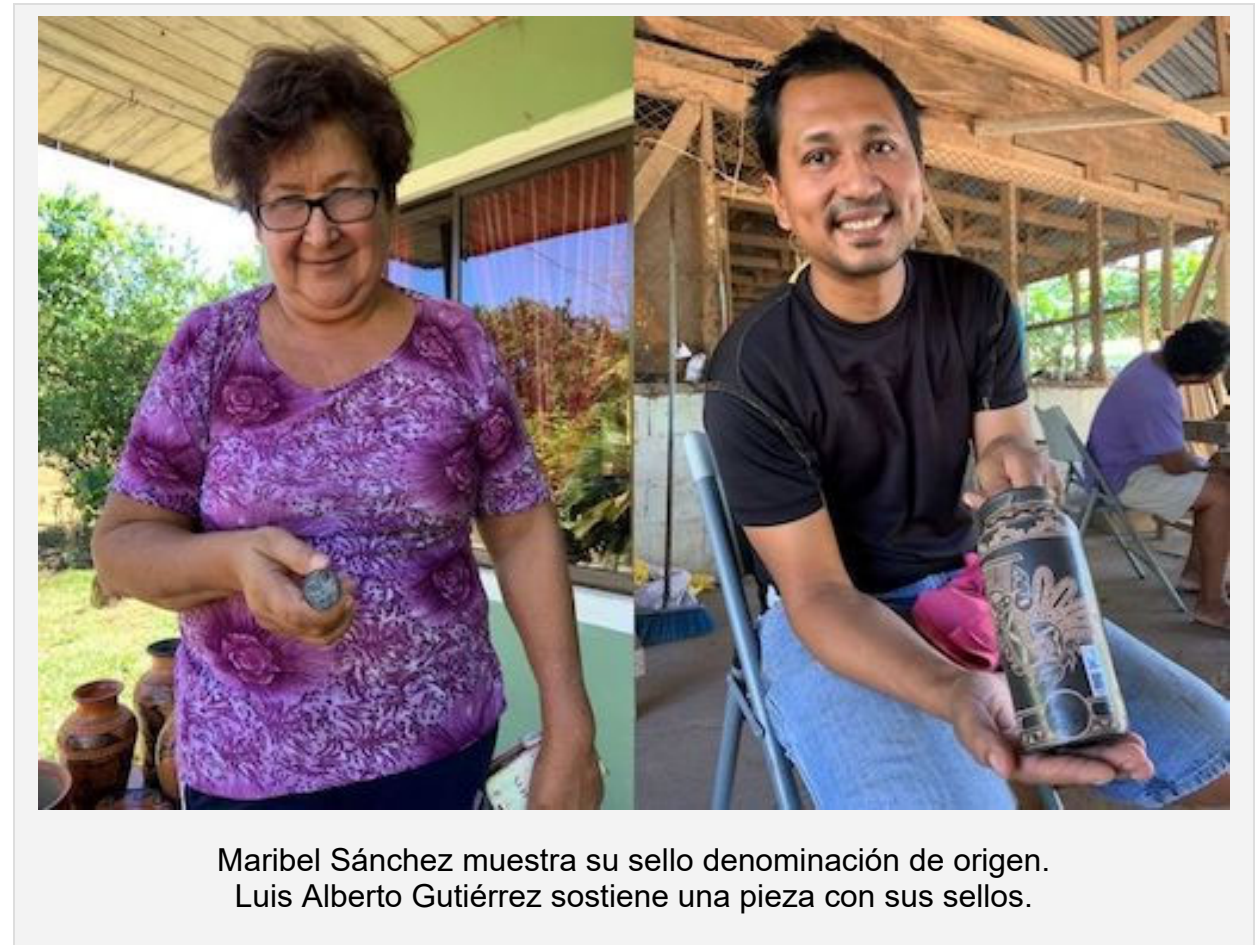

Mientras la CoopeSanGuai funciona colaborativamente en ambas comunidades, las actividades del Ecomuseo de la Cerámica Chorotega han enfatizado los intereses particulares de San Vicente. Según los involucrados, el Ecomuseo iba a presentar la rica herencia alfarera y a la vez buscar soluciones a problemas comerciales. Se tardó una década para crear una exhibición permanente; miembros de la comunidad asistieron a México para aprender un modelo de formación de museos comunitarios promulgado en Oaxaca para empoderar poblaciones "marginalizadas" (Camarena y Morales 2006). El uso de este modelo generó consenso en temas de la vida cotidiana en la primera mitad del siglo XX. Se usaron fotos u objetos viejos, materias, herramientas, piezas cerámicas, mapas y fotos del paisaje local.

Hasta cierto punto, se cumplieron las expectativas del Ecomuseo, pero el entusiasmo disminuyó por las demoras en conseguir fondos y continuar con el desarrollo de programas. Además, el turismo nunca llegó a un nivel suficiente para crear una economía artesanal próspera en los barrios de San Vicente. El bajo número de visitantes resultó en poca venta y las comisiones por venta en poco ingreso para los artesanos. Aunque la mayoría de las actividades funcionaban por el trabajo voluntario, las ganancias apenas cubrieron el presupuesto con la cuenta de electricidad y el sueldo de una persona para mantener abierto y recibir a visitantes.

El Ecomuseo no ha cumplido su potencial. Con la imposición del modelo de Oaxaca la exhibición no integró aportes de distintos especialistas; hasta ahora se ha inhibido la oportunidad de crear una exhibición que resalte la particularidad de esta herencia alfarera, sus logros técnicos y estéticos. A falta de lograr exhibir piezas arqueológicas, una exhibición de réplicas fieles habría podido establecer la importancia del Ecomuseo en los circuitos turísticos y académicos (Weil 2010). Además, las exhibiciones no resaltan ejemplos de la cerámica representando los valores de excelencia. Eso habría podido apoyar el mercado para piezas más finas e inspirar los esfuerzos artísticos de todos los artesanos (JohnsonOrtiz 2005). Mientras tanto, siempre más personas hacen piezas corrientes y por la competencia los precios bajan hasta que pocos ganan suficiente para vivir de la alfarería. 
Las posibles respuestas al futuro de la tradición alfarera de Nicoya han sido proporcionadas por diversos actores artesanales e institucionales (1).

\subsection{Voces de los actores}

A finales de enero de 2021, los artesanos trabajaban en sus casas, aunque al inicio de la pandemia muchos dejaron de hacer cerámica. El turismo en Costa Rica llegó casi a cero y nadie visitó las comunidades durante varios meses. Así, los artesanos dedicados regresaron a trabajar debido a que "sentían la necesidad" de hacerlo.

Las comunidades están activas y hay planes de trabajo de parte de las organizaciones. Un hotel de playa pidió mil piezas con sello de denominación de origen. Según se pudo constatar, hay colaboraciones entre socios transitorios para cumplir con el encargo. No todos se benefician de estas solicitudes, pero siguen trabajando y venden "barato" a los intermediarios.

El Ecomuseo casi no tiene visitantes. Como ha sido la regla, quienes entran por Santa Cruz llegan primero a Guaitil, donde encuentran talleres-tiendas junto al camino y alrededor de la plaza de futbol; muy pocos se aventuran para ir hasta San Vicente. Los artesanos que trabajan solos y residen en las afueras son los más vulnerables ante un comercio desequilibrado, participan menos de las organizaciones formales y son propensos a visiones negativas del futuro.

Al contrario, quienes son líderes de las organizaciones despliegan visiones positivas. Es propio de los líderes de estas comunidades alfareras mostrar actitudes como el optimismo. Logran ver hacia el futuro con las herramientas que ya poseen o que deben aprender; toman iniciativas para sí y para sus comunidades, por lo que están dispuestos a imponer disciplina, pero hábiles al diálogo con sus vecinos y autoridades. Los líderes carismáticos o no, tienen en común autoconfianza; algunos son artesanos sobresalientes.

En líneas generales las opiniones sostenidas por los artesanos basculan entre quienes consideran que "si los niños no aprenden, no va a haber futuro" y, por lo tanto, "la artesanía se va a acabar", hasta quienes consideran que hay que "seguirle dando" porque la gente volverá a lo tradicional y "hará barro" para cocinar por lo que habrá que "volver a la tinaja, otra vez". En general, quienes apuestan por la pervivencia entienden la unión y la perseverancia como dos de las claves a futuro y así, mantienen la esperanza. "Tengo fe que va a llegar un momento próspero", porque "así como tomamos de los indígenas, en el futuro van a tomar de nosotros".

Los actores institucionales externos aportan puntos de vista variados. Sobre la artesanía: "Deberían crear como artistas y no como artesanos". "Los artesanos se reinventan, no son un grupo homogéneo, hay que ver a los sujetos". "Estoy convencido que la creatividad es una ventana de esperanza". Sobre las organizaciones: "El Ecomuseo puede ayudar a continuar la tradición siempre que se fortalezca la organización comunitaria". "No se puede contar con el Estado, hay intereses políticos que cambian y los procesos comunitarios pueden verse afectados". Sobre la identidad: "No se va a perder porque a los guanacastecos les interesa conservar su identidad".

\subsection{Retos del futuro}

La introducción del molde en forma de comal es una innovación que no existía en épocas antiguas, pero sí en el siglo XIX; el horno de colmena sustituyó al horno abierto; el rol y los colores artificiales son innovaciones más recientes. En conjunto estos cambios cualitativos transformaron la herencia. La industria se renovó con el impulso del turismo y la participación masculina en la confección. Esta es una herencia dinámica que cambia sus productos ante la demanda del mercado y la intervención de diversos agentes externos e internos. ¿Cómo afectan los procesos globales la producción local? Con la pandemia y sin turismo, cambian los productos y los consumidores. ¿Cómo van a cambiar los productores y la forma de hacer alfarería en Nicoya en el futuro?

La producción de las réplicas de piezas arqueológicas y los suvenires para un mercado turístico global estimuló la producción artesanal e incluso la llevó a niveles artísticos que antes no fueron evidentes. En la actualidad el consumidor nacional ha incrementado la demanda de comales, ollas y tinajas, lo que ha permitido el trabajo, pero no estimula la creatividad. 
mejoras técnicas son producto de las experiencias de los artesanos dentro de las cooperativas y a nivel individual. Algunos artesanos con habilidades artísticas desarrollaron ideas que fueron acumuladas. Las capacitaciones de expertos externos también impulsaron cambios. Al tratarse de una tradición, un artesano desarrolla el proceso y un artista logra crear piezas donde trasciende la tradición y propone o reinterpreta de manera notable piezas únicas, técnicamente adecuadas y bellas. Sin embargo, el mercado favorece la venta de suvenires baratos e inhibe que los artesanos hagan piezas finas para reproducir su vida.

Los individuos desarrollan sus propias maneras individuales por lo que sus colegas pueden reconocer quién hizo una determinada pieza. Hay individuos que se quejan porque los copian, mientras que otros consideran que es para beneficio colectivo y así han aprendido los unos de los otros. Todas las tradiciones cambian, en algunos contextos cambian de manera lenta, en otras épocas ocurre rápido. En los últimos 50 años estuvo latente el cambio; aunque se han hecho algunas piezas de la misma manera, se innovaron materiales y técnicas que están presentes hoy, aunque no se sabe si perdurarán. Del pasado lejano no es posible saber quién introdujo una innovación, solo su aceptación al ser reproducida en el tiempo.

El valor de denominación de origen radica en que se resguarda un conocimiento (propiedad intelectual) de una colectividad con tradición única en el espacio, con los materiales y el saber hacer, lo que sirve para distinguirla y respaldar a sus artesanos y al país. Los artesanos cumplen con los signos distintivos en cada obra para portar el sello. Los aportes de la arqueología y antropología social son necesarios en la identificación de los elementos tradicionales, autóctonos, continuos, nuevos y transformados. Por eso la denominación de origen busca que se mantengan elementos tradicionales, pero no inhibe que haya propuestas innovadoras, que se redefinan los elementos.

El papel de las organizaciones locales ha sido fundamental en estas comunidades, tanto para enlazar los individuos con el Estado, como para canalizar recursos. Sin embargo, las organizaciones compiten con los individuos, si ellos no las consideran representativas; en determinados momentos de la historia reciente, así ha sido. Por eso algunos individuos ven a las organizaciones para el beneficio personal. Esto nutre el individualismo basado en una experiencia histórica: a nivel local hay fracasos organizativos; a nivel regional los abusos del poder político y una estructura económica en desventaja para los campesinos; y a nivel global, el énfasis del capitalismo en la búsqueda y consolidación del beneficio individual. Las comunidades mantienen lazos de parentesco estrecho, se trata de familias extendidas. Esto favorece espacios de sociabilidad que impulsan al trabajo colaborativo y la reciprocidad. Sin embargo, estos lazos se debilitan cuando se trata de asegurar una posición económica individual.

Este es el caso del suministro de arcilla. Ha sido latente la falta de solidaridad entre vecinos para favorecer su acceso. El Estado no ha logrado solucionar una situación que requiere el trabajo articulado. La CoopeSanGuai trabaja junto a las autoridades para este fin; el camino ha sido tortuoso, pero probablemente el único posible.

Para cumplir la potencialidad del Ecomuseo se requiere la participación de la comunidad, tanto como la ayuda externa y la presencia del Estado a través de sus capacidades instaladas, recursos y marco legal. Las comunidades necesitan capacitación, orientación e instrucción para enfrentar sus desafíos. Los museos comunitarios son una oportunidad de aprendizaje, gestión, fortalecimiento de procesos identitarios, fuentes continuas de fondos y organización local robusta. La entidad que vela por eso, la Dirección de Museos, no ocupa un lugar en el organigrama del Museo Nacional de Costa Rica, la institución donde está hospedada. Esto afecta el flujo de recursos y colaboraciones.

En pleno auge del turismo, los artesanos desarrollaban su aprendizaje en la alfarería como actividad secundaria. Buscaban ejercer otras carreras con trabajos remunerados. Si bien los niños siempre aprendieron el trabajo en sus propios hogares, ayudando en tareas simples y "jugando con el barro", el oficio lo ejercen solo ciertos individuos. Hoy día, los propios padres no incentivan el aprendizaje. De hecho, los líderes esperan que el maestro de artesanía les enseñe. ¿Por qué y para qué deben aprenden los niños la alfarería? ¿Qué pasará con los niños? La tradición se monta sobre la herencia que se transmite, si no hay aprendices, la tradición no puede perpetuarse. Este es el mayor reto. No solo se transmiten conocimientos sino identidad.

La alfarería tradicional de Nicoya otorga un sentido de pertenencia a Guanacaste y a su herencia cultural que se reconoce por su historia, paisaje y clima. La alfarería es un símbolo fundamental que protege y guarda una identidad entre grupos que carecen de poder político o económico. En ese sentido, la 
tradición perdurará con cambios visibles hoy; así ha sido en su historia: el pasado es presente, el presente es futuro.

\section{Notas}

1. Artesanos: Maribel Sánchez Grijalba, Nury Marchena Grijalba, Luciano Grijalba Villafuerte, Javier Marchena Chavarría, Ilsia Chavarría Chavarría, Elpidido Chavarría Chavarría, Deivy Ramírez, Francis Dimas Chavarría, Blanca Espinoza, Gredy Chavarría Grijalba, Tomasa Grijalba, Odin Chavarría, Jonathan Grijalba Chavarría, Doralisa Grijalba Villafuerte, Marcos, Vicente y Marta Espinoza Grijalba, Derix Briceño Espinoza, Luis Alberto Gutiérrez Gutiérrez, Carlos Grijalba Chavarría. Actores institucionales: Vera Vargas León Ministerio de Cultura y Juventud, Ivette Guier y Fernando Camacho Mora Universidad de Costa Rica, Ronald Martínez Villareal Dirección de Museos.

\section{Bibliografía}

Abel-Vidor, Suzanne (y otros)

1990 "Principales tipos cerámicos y sus variedades de la Gran Nicoya", Vínculos (San José), n $13:$ 35-318.

Alfaro, Anastasio

1914 "La cerámica de Chira”, Pandemónium, n 9: 689-691.

Barrantes, Ramiro

1993 Evolución en el trópico. San Pedro, Editorial Universidad de Costa Rica.

\section{Baudez, Claude}

1967 "Rechèrches archéologiques dans le Valleé du Tempisque, Guanacaste, Costa Rica", Travaux et Memoires de l'Institut des Hautes Etudes de l'Amerique Latine (París), nº 18: 1-402.

Bishop, Ronald (y Frederick Lange)

2013 "Frederick R. Mayer's legacy of research support: the prehispanic schools of Greater Nicoya”, en M. Young-Sánchez (ed.), Precolumbian art and archaeology: art and archaeology: essays in honor of Frederick R. Mayer. Denver, Denver Art Museum: 27-46.

Braswell, Geoffrey (y otros)

2002 "La antigua Nicaragua, la periferia sudeste de Mesoamérica y la región maya: interacción interregional (1-1522 d. C.)", Mayab, no 15: 19-39.

Brulotte, Ronda L.

2012 Between art and artifact: archaeological replicas and cultural production in Oaxaca, Mexico. Austin, University of Texas Press.

Camacho Mora, Fernando (y Geissel Vargas)

2017 "Informe final evaluación arqueológica restauración estructuras de la iglesia de San Blas de Nicoya" (segunda temporada), Guanacaste, Nicoya. Manuscrito. San José, América Ingeniería y Arquitectura.

Camarena Ocampo, Cuauhtémoc (y Teresa Morales)

2006 "Community museums and global connections, the Union of Community Museums in Oaxaca", en Iván Karp y otros (coord.), Museum frictions: public cultures/global transformations. Durham, Duke University Press: 322-344.

Chang, Guiselle

2019 "Riesgos de la producción cerámica tradicional de Nicoya e interacción de la diversidad patrimonial", Vínculos, $n^{\circ}$ 39: 115-134.

Coe, Michael (y Claude Baudez) 
1961 "The zoned bichrome period in northwestern Costa Rica", American Antiquity, n 26: 505-515.

Constenla, Adolfo

1991 Las lenguas del Área Intermedia: introducción a su estudio areal. San Pedro, Editorial de la Universidad de Costa Rica.

Dennet, Carrie (y otros)

2019 "Re-evaluating ceramic economy at Ayala (AD 1-1250), Granada, Nicaragua, Cuadernos de Antropología, $\mathrm{n}^{\circ}$ 29: 1-34.

https://revistas.ucr.ac.cr/index.php/antropologia/article/view/34089.

Edelman, Marc

2005 Campesinos contra la globalización: movimientos sociales rurales en Costa Rica. San José, Editorial Universidad de Costa Rica.

FMI

2021 "Comunicado de prensa. № 21/53, 1 de marzo de 2021".

https://www.imf.org/es/News/Articles/2021/03/01/pr2153-costa-rica-imf-exec-board-approves-36-mo-ext-

arr-eff-concludes-2021-art-iv-consultation.

Fonseca, Oscar (y Richard Cooke)

1993 "Historia antigua del sur de América Central: una contribución al estudio de la Región Histórica Chibcha-Chocó", en Robert Carmack (ed.), Historia antigua de América Central: del poblamiento a la conquista. Madrid, Siruela: 217-281.

Freire Paz, Elena

2017 "Estereotipos de barro: mulleres na olería tradicional galega", Boletín galego de literatura, n 50: 6 .

González, Fernando (y Carlos Zamora)

2002 Comunidades ceramistas. Guaitil y San Vicente de Nicoya. San José, Centro de Investigación y Conservación del Patrimonio Cultural, Ministerio de Cultura y Juventud.

https://pdfslide.net/documents/comunidades-ceramistas-guaitil-y-san-vicente-de-guanacaste.html.

Guadamuz, Diego

2019 "Localización de recursos útiles de arcillas para la producción de cerámicas en la región chorotega de Costa Rica". Tesis de Licenciatura. Escuela Centroamericana de Geología. San Pedro, Universidad de Costa Rica.

Guier, Ivette

2007 "Isla de Chira: santuario o reducto agónico de la cerámica precolombina", Herencia, n 20: 73-81.

http://revistas.ucr.ac.cr/index.php/herencia/article/view/10034.

Hernández, Mireya (y Flora Marín)

1975 Guaitil, una reserva autóctona en peligro. San José, Editorial Fernández-Arce.

Herrera, Anayensy

2001 "Tecnología alfarera de grupos ribereños de la cuenca del golfo de Nicoya durante los períodos Bagaces (300-800 d. C.) y Sapoá 800-1350 d. C.)". Tesis de Licenciatura en Arqueología. Escuela de Antropología y Sociología. San Pedro, Universidad de Costa Rica.

2004 "La tortilla nuestra de cada día, dánosla hoy y perdona nuestras omisiones", en Carmen Araya y Margarita Bolaños (ed.), Retos y perspectivas de la Antropología Social y la Arqueología en Costa Rica a Principios del Siglo XXI. San Pedro, Editorial Universidad de Costa Rica: 43-51.

Hoopes, John (y Oscar Fonseca Zamora)

2003 "Goldwork and Chibchan Identity: Endogenous Change and Diffuse Unity in the Isthmo-Colombian Area", en Jeffrey Quilter y John W. Hoopes (ed.), Gold and power in ancient Costa Rica, Panama, and Colombia. Washington, DC, Dumbarton Oaks: 49-89.

Hopper, Kate

1994 "Adaptation and art, the impact of tourism on the ceramics and the Social organization of work in San Vicente, Nicoya, Guanacaste". San José, Central American Field Program, Associated Colleges of the Midwest. 


\section{Howard, Patricia}

1979 "A restudy of the Guaitil cooperative, Guanacaste". San José, Central American Field Program, Associated Colleges of the Midwest.

Ibarra, Eugenia

2020 "Apuntaciones etnohistóricas para una arqueología de La Gran Nicoya como región histórica. Una mirada desde el siglo XVI", Vínculos, nº 40: 1-34.

\section{ICT}

2021 "Monitoreo Turístico quincenal. Mayo 2021".

https://www.ict.go.cr/es/estadisticas/informes-estadisticos.html.

Johnson-Ortiz, Aaron

2005 "Appreciating the 'work' in the artwork, handmade ceramics from San Vicente de Nicoya, Costa Rica”, Anthropology of Work Review (Arlington), n 26: 28-33.

Joyce, Rosemary

1993 "The construction of the Mesoamerican frontier and the mayoid image of Honduran polychromes", en Mark Miller Graham (ed.), Reinterpreting prehistory of Central America. Niwot, University Press of Colorado: 51-101.

Lange, Frederick

2004 "Gordon Willey y el concepto de Área Intermedia: conceptos, contribuciones y perspectivas", Revista de Arqueología del Área Intermedia (Bogotá), nº 6: 27-50.

Marcos Arévalo, Javier

2010 "El patrimonio como representación colectiva. La intangibilidad de los bienes culturales", Gazeta de Antropología, $\mathrm{n}^{\circ} 26$ (1). http://hdl.handle.net/10481/6799.

McCafferty, Geoffrey (y Carrie L. Dennett)

2013 "Ethnogenesis and hybridity in proto-historic Nicaragua", Archaeological Review from Cambridge, $\mathrm{n}^{\circ}$ 28: 191-215.

https://www.academia.edu/4436719

12013 Ethnogenesis_and_Hybridity_in_Proto_Historic_Period_Nicaragua.

2014 "El horizonte cerámico de engobe blanco del postclásico temprano de México y Centro América", Memorias Revista Mi Museo y Vos, nº 8: 20-30.

http://www.granadacollection.org/Revista\%20Mi\%20MuseoNo28.pdf.

Meléndez, Carlos (ed.)

1974a Viajeros por Guanacaste. San José, Ministerio de Cultura, Juventud y Deportes.

1974b "Nicoya y sus templos históricos", Revista de la Universidad de Costa Rica, n 38: 59-72.

http://revistas.ucr.ac.cr/index.php/ucr/article/view/22510.

Molina, Iván (y Steven Palmer)

2007 Historia de Costa Rica. San Pedro, Editorial Universidad de Costa Rica.

PEN

2020 Estado de la Nación 26. San José, CONARE-PEN. https://estadonacion.or.cr/informes/.

Reents-Budet Dorie (y otros)

2017 "Intercambio de preciosidades entre los mayas de Mesoamérica y los chibchas de Costa Rica: el caso de las placas de jade y discos de pizarra maya encontrados en Costa Rica", en Bárbara Arroyo y otros (ed.), XXXI Simposio de investigaciones arqueológicas en Guatemala 2017, Tomo I, Guatemala, Ministerio de Cultura y Deportes, Instituto de Antropología e Historia, Asociación Tikal: 131-142.

Reyes, Eduardo

2009 "Unidad y heterogeneidad durante el período Formativo en Costa Rica (2000-300 a. C.): una propuesta de interacción cultural”, Cuadernos de Antropología (San Pedro), n 19: 57-74.

https://revistas.ucr.ac.cr/index.php/antropologia/article/view/6873.

Rubí, Julián (y Daniel Rueda)

2011 "El relevo de género en la elaboración alfarera. El caso de las comunidades de Guaitil y San 
Vicente, provincia de Guanacaste, Costa Rica", Perspectivas Rurales. Nueva Época (Heredia), no 19 : $111-123$.

https://www.revistas.una.ac.cr/index.php/perspectivasrurales/article/download/3382/3242/.

Salgado, Silvia (y Ricardo Vázquez)

2006 "Was there a Greater Nicoya Suarea during the postclassic? Vínculos, n² 29: 1-16.

Shaw, Sandra (y Melissa Steinbauer)

1973 "Pottery making in rural Costa Rica". San José, Central American Field Program, Associated Colleges of the Midwest.

Sibaja, Luis (y Chester Zelaya)

2015 Nicoya su pasado colonial y su anexión o agregación a Costa Rica. San Pedro, Editorial Universidad Estatal a Distancia.

Solis, Felipe (y Anayensy Herrera)

2011 "Mesoamericanos en la Bahía Culebra", Cuadernos de Antropología, n² 21: 1-31.

http://repositorio.ucr.ac.cr/bitstream/handle/10669/13281/1966-3082-1-SM.pdf?sequence=1\&isAllowed=y.

Stocker, Karen

2000 "No somos nada": Ethnicity and three dominant and contradictory indigenist discourses in Costa Rica. Research Paper Series, $n^{\circ}$ 35. Albuquerque: Department of Anthropology, University of New Mexico.

Stone, Doris

1950 "Notes on present-day pottery making and its economy in the ancient Chorotegan area", Middle American Research Records, $\mathrm{n}^{\circ}$ 1: 269-280.

Vega, Andrés (ed.)

1956 Documentos para la historia de Nicaragua. Tomo XIV (1545-1558). Madrid, Imprenta y Litografía Juan Bravo 3.

http://memoriacentroamericana.ihnca.edu.ni/index.php?id=251\&tx ttnews\%5Btt news $\% 5 \mathrm{D}=2170$ \&

cHash=a450939b423618fa5c7932b08a92263b.

Wagner, Philip

1974 "Nicoya: una geografía cultural", Revista de la Universidad de Costa Rica, nº 3: 163-191.

Weil, Jim

2001 "Un ecomuseo para San Vicente: artesanos de cerámica y turismo cultural en Costa Rica", Herencia (San Pedro), n 3: 137-154.

2004 "Virtual antiquities, consumption values, and the cultural heritage economy in a Costa Rican artisan community", en Cynthia Werner y Duran Bell (comp.), Values and Valuables: From the Sacred to the Symbolic. Walnut Creek, AltaMira Press: 231-256.

2010 "Cambios y continuidades en una industria alfarera de la península de Nicoya desde mediados del siglo XX", Vínculos, n³3: 105-136.

Weil, Jim (y Anayensy Herrera)

2014 "La herencia alfarera en la península de Nicoya. Persistencia de una tradición", Cuadernos de Antropología, $\mathrm{n}^{\circ}$ 24: 25-47.

DOI 10.15517/CAT.V24I2.17789 / https://revistas.ucr.ac.cr/index.php/antropologia/article/view/17789/0. 